\title{
Review of low-temperature plasma nitrogen fixation technology
}

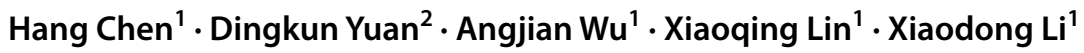 \\ Received: 16 February 2021 / Revised: 1 April 2021 / Accepted: 9 April 2021 / Published online: 8 July 2021 \\ (c) Zhejiang University Press 2021
}

\begin{abstract}
Nitrogen fixation is essential for all forms of life, as nitrogen is required to biosynthesize fundamental building blocks of creatures, plants, and other life forms. As the main method of artificial nitrogen fixation, Haber-Bosch process (ammonia synthesis) has been supporting the agriculture and chemical industries since the 1910s. However, the disadvantages inherent to the Haber-Bosch process, such as high energy consumption and high emissions, cannot be ignored. Therefore, developing a green nitrogen fixation process has always been a research hotspot. Among the various technologies, plasma-assisted nitrogen fixation technology is very promising due to its small scale, mild reaction conditions, and flexible parameters. In the present work, the basic principles of plasma nitrogen fixation technology and its associated research progress are reviewed. The production efficiency of various plasmas is summarized and compared. Eventually, the prospect of nitrogen fixation using low-temperature plasma in the future was proposed.
\end{abstract}

Keywords Plasma $\cdot$ Ammonia synthesis $\cdot$ Nitrogen oxides $\cdot$ Plasma activated water

\section{Introduction}

Nitrogen fixation refers to the formation of nitrous compounds (such as ammonia, ammonium, and nitrate) from nitrogen molecules and other reactants, used in industry and agriculture. Nitrogen fixation sustains the nitrogen cycle in nature, and is also one of the most important industrial activities in the world. The Haber-Bosch process produces more than $90 \%$ of the world's ammonia and feeds $40 \%$ of the world's population [1], which is recognized as "the most important invention in the twentieth century." However, as a capital and industry intensive industry, the energy costs and environmental problems associated with the Haber-Bosch process are becoming increasingly problematic. The Haber-Bosch process consumes 1\%-2\% of global energy capacity every year, and emits more than 300 million tons

\footnotetext{
Angjian Wu

wuaj@zju.edu.cn

Xiaodong Li

lixd@zju.edu.cn

1 State Key Laboratory of Clean Energy Utilization, Department of Energy Engineering, Zhejiang University, Hangzhou 310027, China

2 College of Metrology and Measurement Engineering, China Jiliang University, Hangzhou 310018, China
}

of carbon dioxide. In addition, a large amount of ammonia containing wastewater produced during the production process is difficult to recover, resulting in secondary environmental pollution [2]. Due to the high bond energy $(9.8 \mathrm{eV})$ and stable chemical properties of $\mathrm{N}_{2}$, the Haber-Bosch process requires large-scale facilities and well-planned production to achieve economic and reliable nitrogen activation and ammonia synthesis at high temperatures and pressures $\left(350-550^{\circ} \mathrm{C}, 150-350 \mathrm{~atm}\right)$. However, it is difficult to obtain reliable nitrogen sources in economically backward or remote areas, which further aggravates the uneven distribution of global resources (see Fig. 1).

Therefore, to develop a sustainable, low-carbon, and economic nitrogen fixation technology has gradually become the research hotspot, despite the attendant technical difficulties. This development will surely trigger a second nitrogen fixation revolution. Among the many nitrogen fixation technologies (such as electrocatalytic, photocatalytic, biological, and plasma technologies), low- temperature plasma nitrogen fixation is one of the most promising methods due to its advantages of small scale, mild reaction conditions, and flexible and controllable parameters. In contrast with the Haber-Bosch process and the early Birkeland-Eyde process (thermal plasma method for $\mathrm{NO}_{x}$ synthesis), a lowtemperature plasma can inject most of the input energy into the activation of $\mathrm{N}_{2}$ at room temperature and atmospheric pressure. Theoretical calculations indicated that the energy 


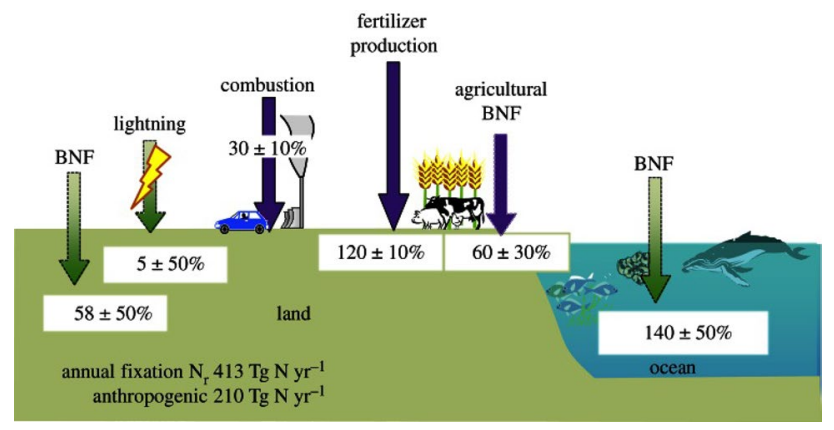

Fig. 1 Global nitrogen fixation, natural and anthropogenic in both oxidized and reduced forms through combustion, biological nitrogen fixation (BNF), lightning, and fertilizer (Haber-Bosch process). Reprinted from [3] with permission

consumption of nitrogen fixation by a low-temperature plasma was lower than that of standard ammonia synthesis determined by thermal dynamics [1]. Moreover, low-temperature plasma technologies can be eminently compatible with intermittent renewable energies (such as solar energy or wind energy). With the large-scale layout of renewable energy in the world, low-temperature plasma for nitrogen fixation may help convert the excess renewable energies into valuable chemicals and avoid energy wasting, while paves the way for sustainable nitrogen fixation (see Fig. 2).

At present, nitrogen fixation with low-temperature plasma can be divided into two categories: one is the ammonia synthesis reaction by nitrogen reduction; the other is the direct production of $\mathrm{NO}_{x}$ or $\mathrm{NO}_{3}{ }^{-} / \mathrm{NO}_{2}{ }^{-}$by oxidation method. For nitrogen reduction, ammonia synthesis using a low-temperature plasma via the reaction of nitrogen and hydrogen/water, along with renewable energies to achieve zero-emission nitrogen fixation. As for plasma oxidation, the direct use of plasma to oxidize air or nitrogen-oxygen mixture can weaken the demand for high-purity hydrogen and nitrogen. Although nitrogen is fixed in the form of $\mathrm{NO}_{x}$ or $\mathrm{NO}_{3}^{-}, \mathrm{NO}_{2}^{-}$, it is different from nitrogen oxide pollution in industrial exhaust gas or waste liquid, and does not contain $\mathrm{SO}_{2}$, solid particles, dioxins, and other pollutants. Pollutantfree fixed nitrogen can be oxidized into valuable products, such as nitric acid and ammonium nitrate. In this paper, we discuss the basic principles, reactor types, operation conditions, and underlying mechanisms inherent to plasma nitrogen fixation. The technical and economic bottlenecks as well as the development aims of this technology are analyzed in the context of large-scale industrial application.

\section{Nitrogen fixation via low-temperature plasma-driven ammonia synthesis}

\section{Kinetics of ammonia synthesis in individual plasma}

Ammonia synthesis is usually carried out with nitrogen and hydrogen as raw materials [4]. Due to the high stability of the nitrogen triple bond $(9.8 \mathrm{eV})$, ammonia synthesis usually requires high temperatures to optimize the reaction rate and provide the required activation energy. However, the high-temperature reaction environment is not conducive to shifting the chemical equilibrium in the direction of ammonia generation attribute to the nature of exothermic reaction:

$\mathrm{N}_{2}(g)+3 \mathrm{H}_{2}(g) \rightarrow 2 \mathrm{NH}_{3}(g), H=-92.4 \mathrm{~kJ} / \mathrm{mol}$.

In comparison with the thermodynamic Haber-Bosch process with high macro-temperatures, low-temperature plasma provides a high reactive environment under the conditions of low or normal temperature. The energetic electrons in plasma can excite nitrogen and oxygen molecules from ground state, providing various active particles including vibrational molecules, atoms, and radicals to overcome the high energy barrier in nitrogen conversion. For instance, it was reported that the vibrational excitation of nitrogen induced by a low-temperature plasma could reduce the energy barrier via non-thermal Zeldovich mechanism [5], as
Fig. 2 Theoretical energy consumption of various nitrogen fixation methods. Reprinted from [1] with permission

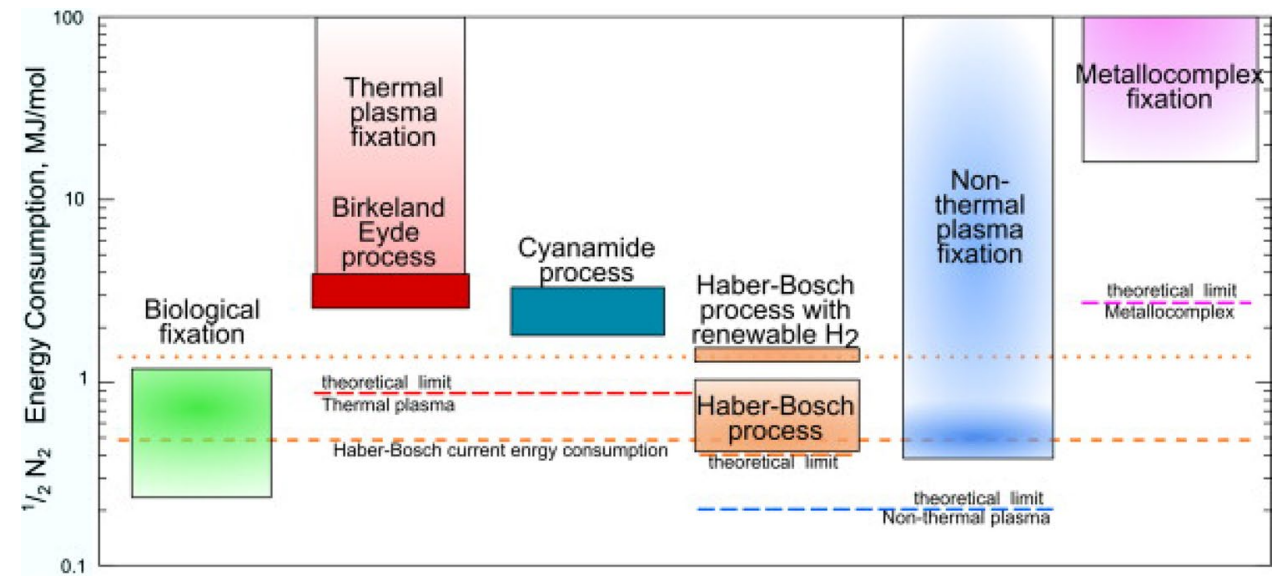


shown in Table 1. Moreover, plasma and nitrogen vibrational excitation can improve catalyst activity, thereby improving reaction efficiency [6].

\section{Ammonia synthesis via plasma coupled with catalysis}

Ammonia synthesis using a low-temperature plasma normally requires a catalyst to improve adsorption, reaction activity, and production selectivity. Among various types of low-temperature plasma, dielectric barrier discharge (DBD) is suitable for atmospheric plasma combined with catalysis. Catalysts in DBD can not only provide energetic electrons for nitrogen-nitrogen-bond excitation, but also active sites for active species for subsequent reactions. They also act as discharge media to improve the plasma stability; based on this, many works are devoted to the design of catalysts to improve the catalytic behavior. Generally, ammonia can be synthesized by individual plasma discharge, while the geometrical parameters of the plasma devices will affect synthesis yield of ammonia in contrast. With the presence of catalysts, it will be more difficult to optimize operating conditions [7, 8]. It is because that the effect of plasma on a catalyst is unidirectional. Plasma may change the structure and morphologies of the catalyst surface, even the inner characteristics, and the catalysts sometimes greatly enhance reaction via the strengthening the interaction of the plasma and catalyst surface [9].

\section{Effect of catalyst material}

The dielectric material should be carefully selected to generate plasmas with sufficient electron energy. For example, piezoelectric ceramics with lower dielectric constant (below 1900) gives both greater energy efficiency and higher ammonia yield than $\mathrm{BaTiO}_{3}$ spheres (1250-10,000 over the temperature range $20-120{ }^{\circ} \mathrm{C}$ ) [10]; while $\mathrm{BaTiO}_{3}$ can be more suitable than materials with quite low

Table 1 Activation energies of the reactions for thermal-catalytic ammonia synthesis ( $\left.E_{\text {a,app-thermal }}\right)$, thermal-catalytic $\mathrm{N}_{2}$ equilibration by isotope exchange reactions with $\mathrm{N}_{15}\left(E_{\mathrm{a}, \mathrm{N} 2 \text { equi }}\right)$, and plasmaenhanced catalytic ammonia synthesis $\left(E_{\mathrm{a} \text { app-plasma }}\right)$. Reprinted from [5] with permission

\begin{tabular}{lcll}
\hline Catalyst & $\begin{array}{l}E_{\text {a,app-thermal }} \\
(\mathrm{kJ} / \mathrm{mol})\end{array}$ & $\begin{array}{l}E_{\mathrm{a}, \mathrm{N} 2 \text { equi }} \\
(\mathrm{kJ} / \mathrm{mol})\end{array}$ & $\begin{array}{l}E_{\text {a,app-plasma }} \\
(\mathrm{kJ} / \mathrm{mol})\end{array}$ \\
\hline $2 \mathrm{Ru} / \gamma-\mathrm{Al}_{2} \mathrm{O}_{3}$ & $60-70$ & $45-60$ & 20 \\
$10 \mathrm{~K}-2 \mathrm{Ru} / \gamma-\mathrm{Al}_{2} \mathrm{O}_{3}$ & $100-115$ & $95-105$ & 41 \\
$5 \mathrm{Mg}-2 \mathrm{Ru} / \gamma-\mathrm{Al}_{2} \mathrm{O}_{3}$ & 104 & & 36 \\
$5 \mathrm{Cs}-2 \mathrm{Ru} / \gamma-\mathrm{Al}_{2} \mathrm{O}_{3}$ & $100-115$ & & 27 \\
\hline
\end{tabular}

dielectric constant like glass (dielectric constant of 4-6) [7]. Alumina spheres were also studied for improving synthesis performance [11]. Bai et al. utilized activated alumina as the dielectric material to produce ammonia with a concentration of $1.25 \%$ under atmospheric pressure without heating - the highest unit energy output was $1.83 \mathrm{~g} /(\mathrm{kWh})$ [12]. $\mathrm{MgO}$ is also selected as a discharge medium for $\mathrm{DBD}$ ammonia synthesis [13].

Ru-based catalysts are also widely used in plasma catalysis for ammonia synthesis using DBD plasma because of the good chemisorption and excitation effect of $\mathrm{Ru}$ on a nitrogen molecule [14, 15]. The simplest catalyst forms are Ru on alumina, magnesia, carbon nanotubes, or oxides of ruthenium [16-19]. The addition of a small amount of oxygen (about $1 \%$ ) to the reaction environment to maintain the presence of $\mathrm{RuO}_{2}$ can significantly increase the concentration of ammonia in the product [17].

Nevertheless, in plasma environment, the catalytic activity may be quite different from that in thermal catalysis. Metals such as $\mathrm{Co}$ and $\mathrm{Ni}$, with weaker nitrogen-binding abilities may be more suitable for ammonia synthesis than $\mathrm{Ru}$. The catalytic activity of such metals may be positively related to the binding energy of their corresponding metal nitrides [9, 20]. The highest nitrogen conversion of $12 \%$ was achieved with a nickel-based catalyst on silica, with $\mathrm{BaTiO}_{3}$ beads as an enhancer [7]. Iwamoto et al. [20] used filamentous metals as internal electrodes for $\mathrm{N}_{2} / \mathrm{H}_{2}$ discharge. The order of initial catalytic effect of various metals was $\mathrm{Au}>\mathrm{Pt}>\mathrm{Pd}$ $>\mathrm{Ag}>\mathrm{Cu}>\mathrm{Fe}>\mathrm{Mo}>\mathrm{Ni}>\mathrm{W}>\mathrm{Ti}>\mathrm{Al}$. The catalytic effect of $\mathrm{Pt}, \mathrm{Pd}, \mathrm{Ag}, \mathrm{Cu}$, and $\mathrm{Ni}$ increased with running time. Metals, such as $\mathrm{Mg}, \mathrm{K}$, and $\mathrm{Cs}$, can act as enhancers, participating in the catalytic reaction as part of a composite catalyst, which obviously promotes the synthesis of ammonia. Their combination with Ru-based catalysts enhances the electron transfer between Ru and adsorbed nitrogen, and improves the distribution of Ru [17, 19]. Metals may volatilize during the discharge process, adhering to the inner wall of the reactor and rendering the surface of the electrode uneven. These may produce a synergistic catalytic effect for ammonia synthesis $[4,20]$. As part of the discharge medium, $\mathrm{MgO}$ can also promote the synthesis of ammonia from DBD by promoting electron transfer [13]. When $\mathrm{MgCl}_{2}$ is filled in DBD for discharge, it can act as an ammonia absorbent, thus increasing ammonia output. Nano-diamond and diamond-like carbon coating $\left(\mathrm{Al}_{2} \mathrm{O}_{3}\right.$ substrate) have been used as catalysts for $\mathrm{N}_{2} / \mathrm{H}_{2}$ discharge [21]. Under the influence of $\mathrm{C}=\mathrm{O}$ bond, oxygen-containing nano-diamond and diamond-like carbon have a significant catalytic effect; while hydrogen-containing nano-diamond can inhibit the formation of ammonia with its $\mathrm{C}-\mathrm{H}$ bond, reducing the conversion rate to even lower than that of pure $\mathrm{Al}_{2} \mathrm{O}_{3}$ (see Fig. 3).

Easily ionized gases, such as $\mathrm{He}$ and $\mathrm{Ar}$, can enhance the reaction rate as well, and even hydrogen itself can influence 
the reactions [22]. Nakajima et al. found that if hydrogen was added as a quenching gas in the afterglow, a better synthesis effect was produced compared with the direct supply of hydrogen in plasma. This may be the result of weakening the inhibition on the nitrogen excitation process caused by hydrogen in plasma zone [23].

\section{Effect of applied discharge conditions}

The ratio of nitrogen to hydrogen in the feed gas is a crucial factor for plasma ammonia synthesis. Compared with nitrogen, hydrogen is easily activated and usually does not figure in restricting the reaction rate. An increase in hydrogen concentration does not improve the intrinsic activity of the catalyst [11]. Due to the stable nitrogen triple bond, the activation and dissociation of nitrogen form the bottleneck of the overall reactions [22]. With a Ru-based catalyst, the optimal $\mathrm{N}_{2} / \mathrm{H}_{2}$ ratio is usually greater than 1. A nitrogen-rich environment increases the probability of collision between nitrogen and electrons, increasing the density of active nitrogen molecules, and therefore increases the probability of a reaction between nitrogen and hydrogen particles. An optimal ammonia output is achieved with a higher $\mathrm{N}_{2} / \mathrm{H}_{2}$ ratio, in the range of 2:1-4:1 [12, 17-19, 24]. However, Mizushima et al. used $\mathrm{Ru}$ on a tubular alumina membrane as catalyst, finding that the optimum $\mathrm{N}_{2} / \mathrm{H}_{2}$ ratio was $1: 3$, in terms of both formation rate and energy efficiency [16]. Generally, the highest ammonia production and the fastest fixation efficiency cannot be achieved under the same working conditions. Aihara et al. reported that, with a copper wire electrode, the maximum ammonia production was attained when the ratio was $1: 3$, while the maximum production rate was attained when the ratio was 2:1 [4]. Similarly, in the filamentary metal discharge, the highest yield is achieved when the ratio is $1: 3$ and the fastest yield when the ratio is $1: 1$ [20]. This implies that when the catalyst is a metal other than $\mathrm{Ru}$, the nitrogen-rich environment does

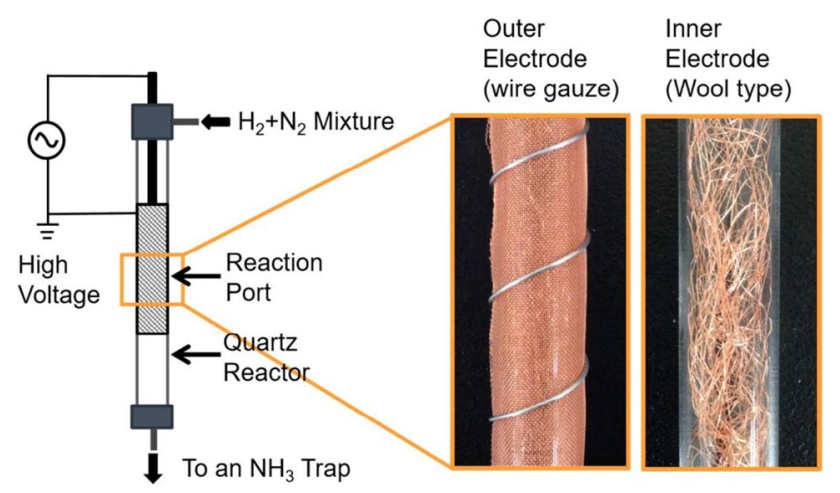

Fig. 3 Apparatus of filamentous metals electrode catalysts by Iwamoto et al. Reprinted from [20] with permission not constitute the best synthesis conditions. When $\mathrm{MgCl}_{2}$ is utilized as the discharge medium and absorbent (unit energy output $20.5 \mathrm{~g} / \mathrm{kWh}$ ), the corresponding optimal ratio is 1:1 [25]. With $\mathrm{BaTiO}_{3}$ and piezoelectric ceramics utilized for discharge dielectrics, the optimum ratio is as low as 1:3, while a high ratio would hinder the production of ammonia [10].

In addition to the ratio of nitrogen to hydrogen, the gas flow rate (treatment capacity) and input power greatly impact productivity. Generally, the smaller the treatment capacity and the higher the power, ammonia of higher concentration is produced. Moreover, a high input power may improve the production rate so as to achieve a better output [11]. The effect of power increase would have marginal depression, and finally negatively affect the overall reaction rate and the activity of the catalyst [24]. Mostly, the output of DBD synthetic ammonia is more than $1 \%$. There are cases where the output is higher than $3 \%$, but the overall output is not significant due to a small treatment capacity (usually of a magnitude of $\mathrm{mL} / \mathrm{min}$ ). Relatively high flow rates and low powers will improve energy utilization, but with a cost of ammonia concentration reduction. The effects of discharge dielectrics may be weakened at high flow rates. For example, the absorption effect of $\mathrm{MgCl}_{2}$ is weakened, reducing the output [25]. Therefore, the trade-off between output and energy consumption needs to be balanced. Until now, the unit energy output of plasma ammonia synthesis has been far beneath that of ammonia synthesis, usually between $0.3 \mathrm{~g} / \mathrm{kWh}$ and $3 \mathrm{~g} / \mathrm{kWh}$. Although there is outstanding output of $35.7 \mathrm{~g} / \mathrm{kWh}$ by plasma [17], the output of the Haber-Bosch process can reach $127 \mathrm{~g} / \mathrm{kWh}$.

In addition, heating also helps to improve the synthesis effect [24]. For a given set of conditions, increasing the reactor temperature can double the ammonia content [12]; but a higher temperature will reduce catalyst activity, so increased heating is not as effective as increased power [11] (see Table 2).

\section{Effect of plasma systems}

Carreon et al. studied the interaction of $\mathrm{N}_{2}$ and $\mathrm{H}_{2}$ on a metal (gallium) surface in an RF plasma [27]. Subsequently, Shah et al. placed metal nets (iron, copper, palladium, silver, and gold) in an RF plasma $\left(0.26\right.$ Torr and $\left.400{ }^{\circ} \mathrm{C}\right)$ to catalyze the reaction between $\mathrm{N}_{2}$ and $\mathrm{H}_{2}$, and found that the catalytic activity of metals may vary greatly with power. For example, at $50 \mathrm{~W}, \mathrm{Ag}$ had the highest activity; at $150 \mathrm{~W}, \mathrm{Pd}$ had the highest activity; and at $300 \mathrm{~W}$, Au had the highest activity. When the power was $300 \mathrm{~W}$, the energy efficiency of ammonia synthesis was in the range of $0.12-0.19 \mathrm{~g}-\mathrm{NH}_{3} / \mathrm{kWh}$, and the highest ammonia yield was $19 \%$. When using molten gallium as a catalyst, an energy efficiency of $0.22 \mathrm{~g}-\mathrm{NH}_{3} / \mathrm{kWh}$ could be achieved at power of $150 \mathrm{~W}$, and 
Table 2 Yields of different plasma-catalytic nitrogen fixation systems

\begin{tabular}{|c|c|c|c|c|c|c|}
\hline Discharge form & Catalyst & $\begin{array}{l}\text { Maximum } \\
\text { output/\% }\end{array}$ & $\begin{array}{l}\text { Maximum } \\
\text { production rate } \\
(\mu \mathrm{mol} / \mathrm{min})\end{array}$ & $\begin{array}{l}\text { Energy } \\
\text { yield } \\
\mathrm{g} /(\mathrm{kWh})\end{array}$ & $\begin{array}{l}\text { Nitrogen conver- } \\
\text { sion rate } \\
(\mathrm{N} / \mathrm{H} \text { ratio })\end{array}$ & Source \\
\hline DBD & Copper wire & 3.5 & 160 & 3.3 & & Aihara et al. [4] \\
\hline DBD & $\mathrm{Ni} / \mathrm{Si}$ & 6.4 & - & - & & Akay et al. [7] \\
\hline DBD & Alumina medium & 1.25 & & 1.83 & & Bai et al. [12] \\
\hline DBD & PZT & & & 0.9 & $2.7 \%(1: 3)$ & Gómez-Ramírez et al. [10] \\
\hline DBD & $\mathrm{PZT}$ & & & & $7 \%(1: 3)$ & Gómez-Ramírez et al. [26] \\
\hline DBD & Nano-diamond & 1.2 & & & $2.3 \%(1: 3)$ & Hong et al. [21] \\
\hline DBD & DLC & 1 & & & $2 \%(1: 3)$ & Hong et al. [21] \\
\hline DBD & Metal wire & 3.5 & About 96 & & & Iwamoto et al. [20] \\
\hline DBD & $\mathrm{Ru} / \mathrm{Mg} / \mathrm{Al}_{2} \mathrm{O}_{3}$ & & & 35.7 & & Kim et al. [17] \\
\hline DBD & $\mathrm{Ru} / \mathrm{Al}_{2} \mathrm{O}_{3}$ & 1.49 & 37 & 1.9 & $0.4 \%(2: 1)$ & Li et al. [18] \\
\hline DBD & $\mathrm{Ru} / \mathrm{Al}_{2} \mathrm{O}_{3}$ & & About 37 & 0.38 & $4.8 \%(1: 3)$ & Mizushima et al. [16] \\
\hline DBD & $\mathrm{Ru} / \mathrm{CS} /$ carbon nanotubes & 3.7 & & 2.3 & & Peng et al. [19] \\
\hline DBD & $\mathrm{MgCl}_{2}$ & & 56 & 20.5 & & Peng et al. [25] \\
\hline
\end{tabular}

Note: In some literatures, the ammonia output is the conversion rate of nitrogen, while in other literatures, it is the ammonia concentration. Therefore, the data quoted here are for reference only

$D L C$ diamond-like carbon PZT Piezoelectric materials

the ammonia yield reached $10 \%$, which was higher than that of Pd. However, when the power increased to $300 \mathrm{~W}$, catalytic activity decreased [28]. If a Ga-In bimetallic catalyst is used, the energy efficiency can be increased to $0.31 \mathrm{~g}-\mathrm{NH}_{3} /$ $\mathrm{kWh}$ at $50 \mathrm{~W}$. More complex catalysts, such as Ni MOF, have better catalytic performance than pure metals (Ni) [29].

When streamer discharge is used for ammonia synthesis without a catalyst, the maximum ammonia concentration is reached with an $\mathrm{N}_{2} / \mathrm{H}_{2}$ ratio of 0.9 , which is not a nitrogenrich environment. When an $\mathrm{MgO}$ coating is added to an electrode as a catalyst, the synthesis effect is improved by 1.54-1.75 times. If methane is used as a hydrogen source, ammonia is produced, and its concentration can reach $8000 \mathrm{ppm}$ at $1.6 \mathrm{~s}$ residence time. However, in this discharge condition, hydrogen is main production, the conversion rate of which can reach 9.1\% [8]. As a raw material, methane resources are more widely distributed than hydrogen. For instance, wastewater treatment is one of the main sources of domestic methane emission in China [30]. Employing ammonia synthesis that uses the methane produced in wastewater treatment means that the waste itself can be 'reused' as a raw material, curbing greenhouse gas emissions.

Ammonia can be synthesized from a mixture of water vapor and nitrogen. When water vapor is used instead of hydrogen gas as a hydrogen source, the selectivity of ammonia in the product can reach $96 \%$, which is much higher than that of nitrite [31]. Such a reaction is enhanced by UV light, which can increase the content of hydrogen radicals and $\mathrm{H}_{2}$ gas on the water's surface, facilitating the reaction between $\mathrm{N}$ and $\mathrm{H}$ to form $\mathrm{NH}_{3}[32,33]$. Kubota et al. applied a nitrogen jet plasma to a water surface and detected the formation of ammonia, but the concentration was far less than that of nitrate. If a $20 \%$ ethanol solution is used instead of water as the hydrogen source, the ammonia production is greatly increased to $3.2 \mathrm{mmol} / \mathrm{L}$, and the nitrate concentration is reduced to the order of $\mu \mathrm{mol} / \mathrm{L}$ [34] (see Fig. 4).

Hawkof et al. synthesized ammonia via a combination of electrocatalysis and plasma discharge. The discharge between the cathode and liquid surface produces highenergy electrons and active nitrogen particles. The electrolyte (sulfuric acid solution) provides hydrogen and absorbs the ammonia produced. Under the reaction atmosphere without air (nitrogen discharge), there are many nitrogencontaining active particles on the liquid surface, and hydrogen production is inhibited. When the current is small, the selectivity of ammonia in the gas product can be as high as $100 \%$ [35].

\section{Nitrogen fixation via low-temperature plasma-driven nitric/nitrite synthesis}

\section{Kinetics of nitrous synthesis in plasma}

There are various forms of discharge, of which the most common are air plasma jet and gliding arc discharge. The plasma comes in direct contact with the liquid surface to produce nitric acid, nitrous acid, and other substances. In the plasma region, nitrogen will be excited to producing $\mathrm{NO}_{2}$ : 


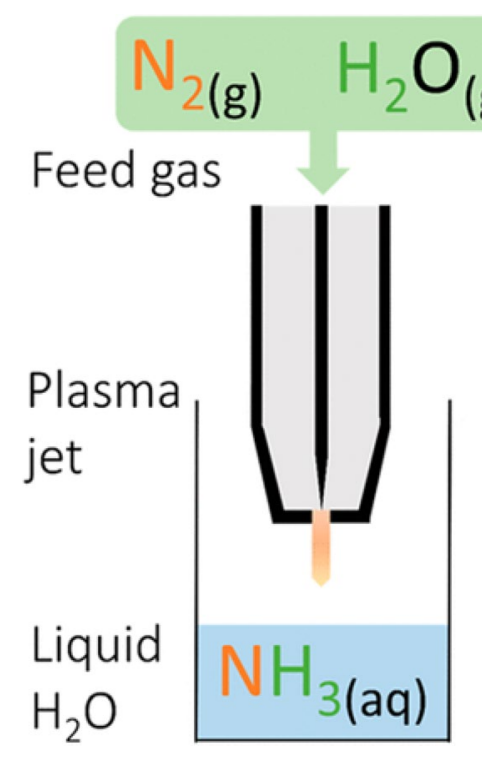

Fig. 4 Plasma jet for ammonia synthesis without hydrogen supply. Reprinted from [31] with permission

$\mathrm{N}_{2}+\mathrm{O} \rightarrow \mathrm{NO}+\mathrm{N}$

$\mathrm{N}+\mathrm{O}_{2} \rightarrow \mathrm{NO}+\mathrm{O}$

$\mathrm{NO}+\mathrm{O} \rightarrow \mathrm{NO}_{2}$

A series of reactions takes place when the nitrogen oxides come into contact with water [36]:

$3 \mathrm{NO}_{2}+\mathrm{H}_{2} \mathrm{O} \rightarrow 2 \mathrm{H}^{+}+2 \mathrm{NO}_{3}^{-}+\mathrm{NO}$

$2 \mathrm{NO}_{2} \rightarrow \mathrm{N}_{2} \mathrm{O}_{4}+\mathrm{H}_{2} \mathrm{O} \rightarrow \mathrm{HNO}_{3}+\mathrm{HNO}_{2}$

$\mathrm{NO}_{2}+\mathrm{NO} \rightarrow \mathrm{N}_{2} \mathrm{O}_{3}+\mathrm{H}_{2} \mathrm{O} \rightarrow 2 \mathrm{HNO}_{2}$

$3 \mathrm{HNO}_{2} \rightarrow \mathrm{HNO}_{3}+2 \mathrm{NO}+\mathrm{H}_{2} \mathrm{O}$.

The generated $\mathrm{NO}$ is oxidized to $\mathrm{NO}_{2}$, which further increases the nitric acid content. In addition to the reaction with water, $\mathrm{NO}_{2}$ reacts with $\mathrm{OH}$ radicals to form nitric acid [37]:

$\mathrm{NO}_{2}+\mathrm{OH} \rightarrow \mathrm{HNO}_{3}$.

The air plasma itself produces an acidification effect. Due to their low ionization potential and high dipole moment, water molecules in air (or from evaporation) and on the liquid surface react with $\mathrm{N}_{2}{ }^{+}$without an activation energy [38]:

$\mathrm{N}_{2}^{+}+\mathrm{H}_{2} \mathrm{O} \rightarrow \mathrm{N}_{2}+\mathrm{H}_{2} \mathrm{O}^{+}$.
Even in the case of low water content, this is one of the main reactions in air plasma, and the generated water ions rapidly react with neutral water molecules:

$\mathrm{H}_{2} \mathrm{O}^{+}+\mathrm{H}_{2} \mathrm{O} \rightarrow \mathrm{H}_{3} \mathrm{O}^{+}+\mathrm{OH}$.

The formation of $\mathrm{H}_{3} \mathrm{O}^{+}$ions and $\mathrm{OH}$ radicals reflects the acidification effect of air plasma, especially the subsequent reactions with $\mathrm{OH}$ radicals in the liquid phase, such as the formation of nitric acid and hydrogen peroxide [39]:

$\mathrm{OH}+\mathrm{OH} \rightarrow \mathrm{H}_{2} \mathrm{O}_{2}$.

$\mathrm{OH}, \mathrm{O}$ and $\mathrm{H}$ radicals, and hydrogen and oxygen cations are generated via collisions between $\mathrm{H}_{2} \mathrm{O}$ molecules and free electrons; the resulting peroxide radicals, $\mathrm{HO}_{2}$, generate $\mathrm{H}_{2} \mathrm{O}_{2}$ :

$\mathrm{HO}_{2}+\mathrm{HO}_{2} \rightarrow \mathrm{H}_{2} \mathrm{O}_{2}+\mathrm{O}_{2}$.

The existence of reactive oxygen species (ROS), reactive nitrogen species (RNS), nitric acid, nitrous acid, and hydrogen peroxide makes such a solution known as plasma activated water (PAW). Strong UV radiation and shock waves in plasma give PAW decontamination, sterilization, and purification properties. As a result, PAW is often used for sterilization, environmental control, seed treatment (promoting germination), soil modification or fertilization, and plant growth promotion [40-44]. An intermediate product with high activity exists in PAW, peroxynitrite $\left(\mathrm{ONOO}^{-}\right)$, which releases $\mathrm{NO}^{+}$when it decomposes, the same substance produced by the ionization of NO. Therefore, in the post-discharge stage, peroxynitrite introduces an oxidation and degradation (for organic matter) effect to the reaction system $[39,45]$ :

$\mathrm{NO}_{2}^{-}+\mathrm{H}_{2} \mathrm{O}_{2} \rightarrow \mathrm{ONOO}^{-}+\mathrm{H}_{2} \mathrm{O}$

$\mathrm{HNO}+\mathrm{O}_{2} \rightarrow \mathrm{ONOOH}$.

In addition, $\mathrm{NO}$ radicals react with $\mathrm{O}_{2}{ }^{-}$or $\mathrm{HO}_{2}$ radicals, and $\mathrm{NO}_{2}$ reacts with $\mathrm{OH}$ radicals, forming peroxynitrite [46, 47]. After its formation on the water surface, peroxynitrite participates in various reactions in water, as shown in Fig. 5.

At high $\mathrm{pH}, \mathrm{ONOOH}^{-}$is stable with a long lifetime, but in $\mathrm{PAW}, \mathrm{ONOOH}^{-}$is extremely unstable and decomposes rapidly to produce various free radicals: $\mathrm{NO}_{2}{ }^{-}, \mathrm{NO}_{3}{ }^{-}$, and other substances [48-50]. Generated free radicals, such as $\mathrm{NO} \cdot$ and $\mathrm{NO}_{2} \cdot$, are highly reactive and cytotoxic, and can be further hydrolyzed or oxidized to produce nitric acid and nitrite; they can also participate, as the main active components, in the degradation of organic waste and sterilization applications. These components exist for a period of time post-discharge, but their levels gradually decrease, leaving stable acid ions $[45,51]$. In addition to the presence of 


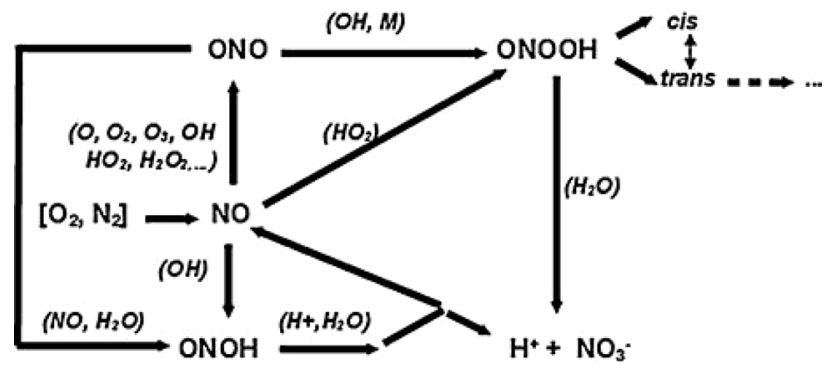

Fig. 5 Reactions of peroxynitrite in water. Reprinted from [39] with permission

peroxynitrite, the presence of nitrite provides the solution with a continuous supply of active particles. Additionally, the peroxynitrite generated from nitrite ions and $\mathrm{H}_{2} \mathrm{O}_{2}$ will then decay into $\mathrm{OH}$ and $\mathrm{NO}_{2}$ radicals. However, nitrite is unstable and will decompose into $\mathrm{NO}$ and $\mathrm{NO}_{2}$.under acidic conditions $(\mathrm{pH}<3.5)$, forming nitric acid [50]. In stable PAW, nitric acid and nitrate are the main components, therefore can be widely used in agriculture for nitrogen fixation.

Ingels et al. proposed the concept of using PAW to recover unstable nitrogen from soil and livestock waste [52]. The annual loss of available nitrogen in soil is $120 \mathrm{Tg}$, which is equivalent to the amount from fertilizer in agricultural production. The loss of nitrogen from human activity (waste food, human, and livestock excreta) is $54 \mathrm{Tg}$. Most nitrogen is lost in the form of $\mathrm{NH}_{3}$ to the atmosphere and water. If part of that could be fixed in soil, by fixing $\mathrm{NH}_{3}$ using PAW, the burden on agricultural fertilizer production would be considerably reduced:

$\mathrm{NH}_{3}+\mathrm{HNO}_{3} \rightarrow \mathrm{NH}_{4} \mathrm{NO}_{3}$.

The nitrogen content in PAW, especially the content of $\mathrm{NO}_{x}^{-}$with its corresponding formation rate, is a key indicator of nitrogen fixation performance. In addition to having a plasma jet on the liquid surface, there are discharge modes in which one or two electrodes are placed in the liquid (usually water or aqueous solution). Although the discharge modes are different, the main products are almost the same $\left(\mathrm{NO}_{2}{ }^{-}, \mathrm{NO}_{3}{ }^{-}, \mathrm{H}_{2} \mathrm{O}_{2}\right)$. Nevertheless, in a liquid with a density much higher than atmospheric gas, not only the excitation of plasma is difficult, but also the diffusion process occurs with difficulty: molecular ionization, secondary emission of electrons, and cation-anion reactions are greatly hindered. Therefore, it is usually necessary to inject air or nitrogen between the electrodes to provide a discharge medium. The plasma excitation conditions are stricter as well that higher and more concentrated voltage is required. An appropriate electrode structure, voltage, and pulse width are needed to achieve the required breakdown conditions, such as vapor bubble ionization. Moreover, the cations, anions, and $\mathrm{pH}$ of the solution can affect discharge [53].

\section{Gas-liquid discharge}

Some studies do not explicitly mention the effect of nitrogen fixation. The solution $\mathrm{pH}$ variation could reflect the nitrous production. The stable anions introduced into solution are $\mathrm{NO}_{x}^{-}$, accompanied by the production of $\mathrm{H}^{+}$. Changes in solution $\mathrm{pH}$, therefore, indicate the effect of nitrogen fixation. Researchers often use $\mathrm{NaOH}$ solution as the treated solution to reflect the air plasma treatment effect $[39,54]$. During the discharge process, the concentration of hydrogen ions in solution increases significantly in a few minutes. The selection of electrode size, discharge distance, and gas flow rate will affect the neutralization time. Buffer solution can be used as the object of discharge treatment to maintain the stability of $\mathrm{pH}$ and prolong the life of active substances (such as peroxynitrite). Bulirca et al. studied the effect of different discharge atmospheres on PAW. As the blade electrodes and water were in the same confined space, discharge in an oxygen atmosphere had almost no nitrogen fixation effect, and only a small amount of $\mathrm{H}_{2} \mathrm{O}_{2}$ was generated. The nitrogen fixation efficiency of air discharge was about twice that of nitrogen discharge. After $15 \mathrm{~min}$ of treatment, $400 \mathrm{~mL}$ nitric acid solution, with a concentration of more than $30 \mathrm{mmol} / \mathrm{L}$, was obtained. However, the power consumption reached $500 \mathrm{~W}$ [37].

The nitrogen content in PAW can be increased by adding salts, such as $\mathrm{NaHCO}_{3}$, before discharge. $\mathrm{NaHCO}_{3}$ reacts with the $\mathrm{NO}$ and $\mathrm{NO}_{2}$ produced by plasma to form nitric acid, which increases the dissolved amount of $\mathrm{NO}_{x}$. Under constant discharge power, the nitrogen content of PAW can increase by 2.9 times [55].

When the reaction area (water surface) is irradiated by UV light, $\mathrm{NH}_{3}$ is generated, as well as nitrogen oxide. At the interface between the plasma and liquid, $\mathrm{N}$ and $\mathrm{H}$ react to form $\mathrm{NH}_{3}$. UV irradiation greatly increases the content of $\mathrm{H}$ radicals and $\mathrm{H}_{2}$ on the water's surface, thus promoting $\mathrm{NH}_{4}{ }^{+}$production in PAW [32]. Peng et al. set a $15 \mathrm{~W}$ UV lamp in a PAW system and selected nitrogen as the plasma carrier gas. The ammonia yield in the PAW reached more than $2 \mu \mathrm{mol} / \mathrm{min}$, though the yield was low compared with the amount of oxidized nitrogen. The total nitrogen fixation rate reached $985 \mu \mathrm{mol} / \mathrm{min}$ [56]. Plasma reactions (such as corona discharge in water) produce UV radiation in the discharge process, stimulating the generation of $\mathrm{H}$ atoms and $\mathrm{H}$ radicals. However, this is not enough to promote the generation of $\mathrm{NH}_{3}$, especially in water. The free radicals are quenched by water molecules soon after they are generated, and this increases the content of $\mathrm{H}_{2} \mathrm{O}_{2}$ in PAW [57].

Discharge in liquid produces unusual effects [58]. The discharge device designed by Peng et al. comprised a vertical cylindrical liquid pool with a partition board in the middle. A small hole in the partition board enabled the gas-liquid mixture to pass through the whole container from bottom to top. 
Two electrodes were placed one on each side of hole to form a concentrated high-density electric field, which could excite the nitrogen and solution mixture to form a plasma. Clearly, the creation of such a plasma needs a large discharge voltage (4-12 kV), and its discharge power can reach 70-140 W. Even at $130 \mathrm{~W}$, the yields of $\mathrm{NO}_{3}{ }^{-}$and $\mathrm{NO}_{2}{ }^{-}$were only 4-6 $\mu \mathrm{mol} / \mathrm{min}$ and 3-5 $\mu \mathrm{mol} / \mathrm{min}$ (also related to the conductivity of the solution). $\mathrm{NH}_{4}{ }^{+}$was obtained, the yield of which was one order of magnitude smaller than the yield of $\mathrm{NO}_{x}^{-}$, and the maximum figure was $0.2 \mu \mathrm{mol} / \mathrm{min}$. $\mathrm{NO}_{x}, \mathrm{NH}_{3}, \mathrm{O}_{3}$, and $\mathrm{H}_{2}$ were generated in the reaction. The concentrations of $\mathrm{NO}_{x}$ and $\mathrm{NH}_{3}$ reached 400 ppm and 240 ppm respectively, which improved the overall nitrogen fixation efficiency of the reaction (see Fig. 6).

When water is added to the discharge gas of the jet plasma, $\mathrm{NH}_{3}\left(\mathrm{NH}_{4}{ }^{+}\right)$is also obtained [31]. The proportion of $\mathrm{NH}_{3}$ (ammonia selectivity) in the nitrogen-containing products is about $15 \%-20 \%$ in the activated water produced by air jet discharge with a certain air humidity. The overall nitrogen fixation level increases with increasing air humidity. For instance, when the gas flow rate is $0.2 \mathrm{~L} / \mathrm{min}$, the relative humidity is $100 \%$, the carrier gas is air and $\mathrm{N}_{2}$, and the $\mathrm{NH}_{3}$ concentration in the solution is $40 \mu \mathrm{mol} / \mathrm{L}$ and $240 \mu \mathrm{mol} / \mathrm{L}$ - the ammonia selectivity reaches $63 \%$. When the carrier gas is $\mathrm{N}_{2}$, the ammonia selectivity reaches its lowest value at $100 \%$ humidity. When the relative humidity of water vapor is $5 \%$, the ammonia selectivity can be as high as 96\%. Ammonia selectivity increases and then decreases with increasing humidity, the critical point of which is always about $60 \%$ for any gas flow rate, reaching its highest value
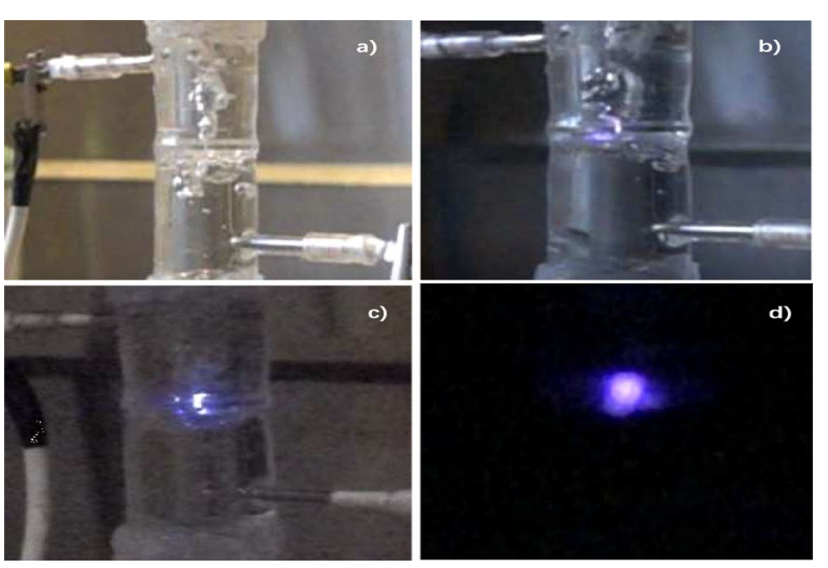

Fig. 6 (a) No voltage applied; (b) plasma discharge under normal lighting; (c) plasma discharge under dim lighting; and (d) plasma discharge under completely dark condition at about $5 \%$. However, total nitrogen fixation increases with increasing gas flow rate. The maximum product concentration is obtained at the maximum flow rate $(1.4 \mathrm{~L} / \mathrm{min})$, which is more than $800 \mu \mathrm{mol} / \mathrm{L}$. The yield seems high at $0.1 \mathrm{~W}$ discharge power, but the activated water as low as $5 \mathrm{~mL}$ was also an important factor.

The above examples show that, without the supply of $\mathrm{H}_{2}$, a low-temperature plasma can still provide hydrogen for nitrogen fixation, and stably synthesize $\mathrm{NH}_{3}$ or other substances under ambient pressure, at room temperature. This highlights the unique catalytic characteristics of plasma. Nevertheless, some similar forms of discharge do not produce $\mathrm{NH}_{3}$. In the gas-liquid pulse discharge device designed by Wandell et al., electrodes were also placed on both sides of the liquid tube, through which flowed a mixture of $\mathrm{N}_{2}$ and water $[59,60]$. The products were $\mathrm{H}_{2} \mathrm{O}_{2}, \mathrm{NO}, \mathrm{NO}_{2}$, $\mathrm{NO}_{2}{ }^{-}$, and $\mathrm{NO}_{3}{ }^{-}$, while $\mathrm{NH}_{3}$ could not be found. It is worth mentioning that the input power and electron density of the reaction device increased with increasing nitrogen content (0-30\%). When the nitrogen content was 30\%, the highest nitrogen fixation efficiency and energy efficiency of the reaction system were achieved simultaneously, providing an advantage that other plasma systems do not. Similarly, only $\mathrm{H}_{2} \mathrm{O}_{2}, \mathrm{NO}_{x}$, and $\mathrm{NO}_{x}^{-}$were produced when water was added to the discharge gas during gliding arc treatment. The addition of water significantly increased the production of $\mathrm{H}_{2} \mathrm{O}_{2}$ $[61,62]$. For nitrogen fixation, the effect of adding water is related to the amount of water and the discharge atmosphere. In air discharge, a large amount of water may increase the content of $\mathrm{NO}_{3}{ }^{-}$by $60 \%$, but in nitrogen discharge, nitrogen fixation is always inhibited.

\section{Separating system for PAW}

In some research, the plasma zone is separated from the liquid zone. For instance, introducing the spark discharged air into the liquid to get nitric acid and nitrous acid [63]. After $21 \mathrm{~min}$ of processing, $1.36 \mathrm{mmol} / \mathrm{L}$ nitric acid was obtained under discharge power of $52 \mathrm{~W}$ - the nitric acid accounts for more than $95 \%$ of overall product. The concentration of nitric acid was $1.53 \mathrm{mmol} / \mathrm{L}$ in nitrogen discharge, higher than that in air discharge. There are still large numbers of active particles in the gas after discharge [64]. Their lifetime is long enough to reach the liquid surface with the gas flow and participate in reactions in the liquid [65]:

$\mathrm{N}_{2}^{+}+\mathrm{H}_{2} \mathrm{O} \rightarrow \mathrm{NO} \cdot+\mathrm{H}$

$\mathrm{NO} \cdot+\mathrm{O} \cdot \rightarrow \cdot \mathrm{NO}_{2}$ 
$2 \cdot \mathrm{NO}_{2}+\mathrm{H}_{2} \mathrm{O} \rightarrow \mathrm{HNO}_{2}+\mathrm{HNO}_{3}$.

Nitric acid is mainly produced from reactions (17)-(19), not from the reactions of $\mathrm{NO} / \mathrm{NO}_{2}$ with liquid. Free radicals (hydrogen and oxygen) from plasma can also react with the solution to provide the oxidability $\left(\mathrm{OH}, \mathrm{O}, \mathrm{H}, \mathrm{H}_{2} \mathrm{O}_{2}\right)$, so that the final product mainly exists in the form of nitric acid. In nitrogen discharge, the concentration of nitrogen related active particles may be higher than other particles, so higher concentration products are obtained (see Fig. 7).

Air gliding arc plasma discharge has been studied in a similar way [66]. It is indicated that a high-frequency gliding arc discharge can improve the synthesis effect and energy utilization rate. Although the discharge power was much higher at $50 \mathrm{~Hz}$, the discharge effect at $5 \mathrm{kHz}$ was still better than that at $50 \mathrm{~Hz}$. After $10 \mathrm{~min}$ of $5 \mathrm{kHz}$ discharge, the highest product concentration was $5.328 \mathrm{mg} / \mathrm{L} \mathrm{NO}_{x}^{-}(78 \mathrm{~W})$, and the highest formation rate was $0.1 \mathrm{mg} /(\mathrm{L} \cdot \mathrm{W})$. Increasing the discharge frequency $(5-10 \mathrm{kHz})$ increased the output by $1 \%-4 \%$. However, when the discharge frequency exceeded $10 \mathrm{kHz}$, the effect of increasing the discharge frequency $(30-80 \mathrm{kHz})$ was not significant, and even produced a negative effect on output. The concentration of $\mathrm{NO}_{x}^{-}$remained around $5.2 \mathrm{mg} / \mathrm{L}$. Similarly, the effect of increasing the gas flow rate (from $1.2 \mathrm{~L} / \mathrm{min}$ to $2 \mathrm{~L} / \mathrm{min}$ ) produced a positive effect, while increasing the flow rate (from $2 \mathrm{~L} / \mathrm{min}$ to $3.2 \mathrm{~L} / \mathrm{min}$ ) did not make a difference on the yield.

In fact, in the mentioned reaction modes, any parameter may affect the output, including (but not limited to) the discharge gas and gas flow rate, electrode geometry and layout, electrode spacing, space between the plasma outlet and liquid surface, and the solution conductivity. When the discharge device and water quality are different for a given volume of activated water, its nitrogen fixation effect may differ greatly [67]. Whether the electrode is placed in water, and whether the electrode in water is the cathode or anode, will have a significant impact on the reaction products, as well $[44,68]$. In addition to the preliminary setting of systems, the conductivity of solution, discharge temperature, and liquid temperature will change during the discharge process. For example, when one electrode is placed above the liquid with small gap, an electrolyte, such as $\mathrm{HNO}_{3}$, produced in the discharge process will not only increase the conductivity of PAW, but will also increase the discharge current and decrease the liquid's surface tension [69]. A decrease in surface tension and increase in conductivity cause a series of changes in the discharge surface, including in its morphology, its discharge distance, and even in its discharge mode- such as a transition from glow discharge mode to spark discharge mode, thus affecting the product (see Table 3).

\section{Nitrogen fixation via low-temperature plasma-driven $\mathrm{NO}_{x}$ synthesis}

\section{Mechanism of nitrogen oxidation in plasma}

Air or air $/ \mathrm{N}_{2} / \mathrm{O}_{2}$ mixed-gas discharge can generate pure and dense $\mathrm{NO}_{x}$ gas ( $\mathrm{NO}$ and $\mathrm{NO}_{2}$ ). This simple discharge method has the potential to reduce the cost of raw materials and the corresponding reactor. In addition, the direct utilization of $\mathrm{NO}_{x}$ (such as in nitric acid and nitrate production) can reduce the need for intermediate links, such as the catalytic oxidation of ammonia to $\mathrm{NO}_{2}$. Especially, high pure $\mathrm{NO}$ is a valuable product in wound treatment and vasodilation.

Microwave plasma, gliding arc plasma, and other lowtemperature plasmas with high energy density can generate high concentration $\mathrm{NO}_{x}$ with a high production capacity. Cold plasmas, such as DBD, need a closed gas pool and a long gas residence time to achieve the same yield. In a discharge environment of low temperature and low-energy
Fig. 7 Nitrogen fixation system proposed by Ingels et al., which is arranged in separating way. Reprinted from [52] with permission

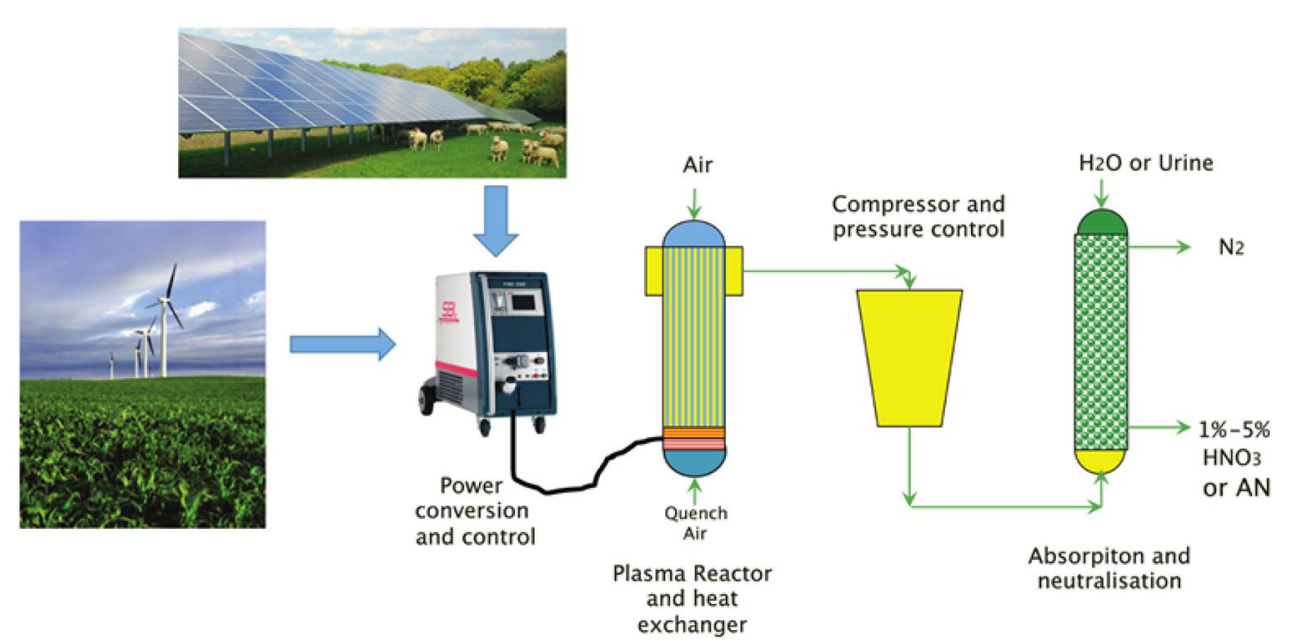


density, ozone will be generated [70, 71]. In nitrogen fixation processes, byproducts are inevitably produced, which will consume energy and active components in the plasma. The existence of ozone accelerates the oxidation process of NO, which constrains the application of product like medical treatment. However, when the temperature reaches $100{ }^{\circ} \mathrm{C}$, ozone decomposes quickly, meaning that there is no ozone in plasmas with high enough energy densities [72].

However, not all high-energy plasmas are suitable for $\mathrm{NO}_{x}$ synthesis. For instance, in spark discharge and streamer discharge, the energy density is very high, but the energy consumption is usually one to two orders of magnitude higher than that in low-temperature plasmas. The high energy efficiency of $\mathrm{NO}_{x}$ synthesis in a low-temperature plasma comes from the advantages inherent to its thermodynamics and kinetics and the characteristics of non-equilibrium state.

In a low-temperature plasma, the major path for breaking the nitrogen triple bond $(9.8 \mathrm{eV})$ is the reaction between vibrational-state nitrogen molecules and oxygen atoms, which has a low energy barrier [73-75]:

$\mathrm{N}_{2}(X, v>12)+\mathrm{O} \rightarrow \mathrm{NO}+\mathrm{N}$

$\mathrm{N}_{2}^{*}\left(A^{3} \Sigma_{u}^{+}\right)+\mathrm{O} \rightarrow \mathrm{NO}+\mathrm{N}^{*}$.

The ground-state nitrogen molecule can be vibrationally excited level-by-level in a plasma. When its vibration attains a certain level, a nitrogen molecule reacts with an oxygen atom:
$\mathrm{N}_{2}(X, v)+\mathrm{N}_{2}(X, w) \rightarrow \mathrm{N}_{2}(X, v+1)+\mathrm{N}_{2}(X, w-1)$

The energy barrier of reaction (20) is about $3 \mathrm{eV}$ [76], which is far lower than the nitrogen triple bond energy. Under certain discharge conditions, such as in a specific reduced electrical field range, the heavy particle excitation mode in a low-temperature plasma can achieve high selectivity. This means that most of the input energy can be utilized for vibrational excitation, thus improving the synthesis efficiency of $\mathrm{NO}_{x}$ [76].

In addition to the reaction in the ground state, the excited gas molecules in the plasma have high reactivity. Metastable $\mathrm{N}_{2}\left(A^{3} \Sigma_{u}^{+}\right)$is an nitrogen molecule with the lowest excitation energy level $(6.17 \mathrm{eV})$, which can be directly generated by the collision of vibrational nitrogen molecules with electrons. The energy level $(7.35 \mathrm{eV})$ of excited $\mathrm{N}_{2}\left(\mathrm{~B}^{3} \Pi_{\mathrm{g}}\right)$ is lower than that of the nitrogen triple bond, which can be generated by vibrational and metastable nitrogen molecules through electronic excitation or association reactions of heavy particles. These activated nitrogen molecules can be decomposed by oxygen atoms to generate $\mathrm{NO}$ and $\mathrm{N}$ atoms. The released $\mathrm{N}$ atoms can further react with oxygen molecules or oxygen atoms to generate NO, forming a reaction chain.

The properties of $\mathrm{O}_{2}$ are much more active. In a lowtemperature plasma, oxygen is easy to excite, and some excited oxygen atoms (such as ${ }^{1} \mathrm{~S},{ }^{1} \mathrm{D}$ ) have a long lifetime, therefore can play a role in promoting the breakdown and stable operation of air plasma. However, the excessive excitation and activation of oxygen (molecules) will lead

Table 3 Nitrogen fixation output of plasma activated water

\begin{tabular}{|c|c|c|c|c|c|}
\hline $\begin{array}{l}\text { Discharge form (discharge } \\
\text { substance) }\end{array}$ & Processing time $(\mathrm{min})$ & Power (W) & $\begin{array}{l}\text { Maximum production rate } \\
\left(\mathrm{NO}_{x}-\left(\mathrm{NO}_{x}\right)+\mathrm{NH}_{4}{ }^{+}\right) \\
(\mu \mathrm{mol} / \mathrm{min})\end{array}$ & $\begin{array}{l}\text { Optimum yield } \\
\text { of nitrogenous } \\
\text { products }\end{array}$ & Source and remarks \\
\hline $\begin{array}{l}\text { Gas liquid mixing } \\
\left(\mathrm{N}_{2}+\text { water }\right)\end{array}$ & - & $74-130$ & 11.2 & $0.072 \mathrm{~g} / \mathrm{W}$ & Peng Peng et al. [58] \\
\hline Jet $\left(\mathrm{N}_{2}\right)$ & - & - & 985 & & $\begin{array}{l}\text { Peng Peng et al. [56] } \\
\text { Ultraviolet irradiation }\end{array}$ \\
\hline $\begin{array}{l}\text { Spark } \\
\text { (air) }\end{array}$ & 21 & 52 & 7.3 & $23.2 \mathrm{nmol} /(\mathrm{J} \cdot \mathrm{S})$ & $\begin{array}{l}\text { Bian Wenjuan et al. [63] } \\
100 \text { mL water }\end{array}$ \\
\hline $\begin{array}{l}\text { Spark } \\
\left(\mathrm{N}_{2}\right)\end{array}$ & 21 & 52 & 7.7 & $20.6 \mathrm{nmol} /(\mathrm{J} \cdot \mathrm{S})$ & $\begin{array}{l}\text { Bian Wenjuan et al. [63] } \\
100 \text { mL water }\end{array}$ \\
\hline $\begin{array}{l}\text { Gliding arc } \\
\text { (air) }\end{array}$ & 10 & $21-78$ & - & $0.1 \mathrm{mg} / \mathrm{L} / \mathrm{W}$ & $\begin{array}{l}\text { Y. Jin et al. [66] } \\
150 \mathrm{~mL} \text { water }\end{array}$ \\
\hline $\begin{array}{l}\text { Liquid surface discharge } \\
\text { (air + water) }\end{array}$ & 30 & - & 7.2 & - & $\begin{array}{l}\text { Lukes et al. [51] } \\
900 \mathrm{~mL} \text { water }\end{array}$ \\
\hline $\begin{array}{l}\text { Jet } \\
\left(\mathrm{N}_{2}+\text { steam }\right)\end{array}$ & 10 & 0.1 & About 0.4 & $15 \mathrm{MJ} / \mathrm{mol} \mathrm{N}$ & $\begin{array}{l}\text { Gorbanev et al. [31] } \\
5 \mathrm{~mL} \text { water }\end{array}$ \\
\hline $\begin{array}{l}\text { Jet } \\
(\text { air }+ \text { steam })\end{array}$ & 10 & 0.1 & About 0.26 & & $\begin{array}{l}\text { Gorbanev et al. [31] } \\
5 \mathrm{~mL} \text { water }\end{array}$ \\
\hline $\begin{array}{l}\text { Gas liquid mixing } \\
\left(\mathrm{N}_{2}+\text { water }\right)\end{array}$ & $127 \mathrm{~ms}$ (water) & $6.37-11.35$ & 78 & $4.8 \mathrm{MJ} / \mathrm{mol}$ & $\begin{array}{l}\text { Wandell et al. [60] } \\
\text { Water flow: } 5 \mathrm{~mL} / \mathrm{min}\end{array}$ \\
\hline
\end{tabular}


to a loss in energy, causing the plasma energy to dissipate in the form of heat $[74,77]$. Generally, the excitation energy of an oxygen molecule is $1-6 \mathrm{eV}$, and the dissociation energy of an excited oxygen molecule is also low. For example, the dissociation energies of $\mathrm{O}_{2}\left(A^{3} \Sigma_{u}{ }^{+}\right)$and $\mathrm{O}_{2}$ $\left(a^{1} \Delta_{g}\right)$ are $1.15 \mathrm{eV}$ and $4.54 \mathrm{eV}$, respectively [78]. They are likely to form oxygen atoms $\left({ }^{3} \mathrm{P},{ }^{1} \mathrm{D},{ }^{1} \mathrm{~S}\right)$ after colliding with electrons, promoting the dissociation of nitrogen, as described by reactions (20) and (21).

\section{Effect of different discharge types}

In 1903, NO production by arc discharge was commercialized in Norway (Birkeland-Eyde process) and was recognized as the preliminary industrial-mature technology for nitrogen fixation. Due to its high energy cost, it was replaced by the Haber-Bosch process in 1913. In recent years, with the rapid development of low-temperature plasma science, the lowest theoretical energy consumption of $0.2 \mathrm{MJ} / \mathrm{molN}$ (MJ per mol $\mathrm{NO}_{x}$ fixed) has rendered the plasma synthesis of $\mathrm{NO}_{x}$ a research hotspot once again [79]. The microwave plasma system designed by Azizov et al. attained an energy consumption as low as $0.29 \mathrm{MJ} / \mathrm{molN}$, almost reaching the lower theoretical energy consumption limit. The system effectively enhanced energy conversion, making the plasma absorb more than $90 \%$ of the input energy. However, the reaction conditions of the system were too harsh. The reaction pressure below 100 Torr, the use of liquid nitrogen cooling system, and electron-cyclotron resonance system limited its industrial application. Nevertheless, the prospect of this direction cannot be ignored. It is estimated that low-temperature plasma nitrogen fixation (synthetic nitric acid) has the potential to reduce $19 \%$ of the global warming problem compared with the traditional Haber-Bosch process [80].

One of the simplest artificial discharges is spark discharge, which is used in the study of $\mathrm{NO}_{x}$ synthesis. Because of the intermittent discharge and small plasma area in spark discharge, the processing capacity is greatly limited (a long discharge time is usually needed). Moreover, the energy efficiency is low, because its properties are close to those of thermal plasma. Cooray et al. utilized air spark discharge to synthesize $\mathrm{NO}_{x}$ and its energy consumption was $20.3 \mathrm{MJ} / \mathrm{molN}$ [81]. Pavlovich et al. designed a multielectrode spark-like discharge device, which discharged at room temperature and atmospheric pressure in a chamber. The discharge form was a combination of glow plasma and electric spark. The higher the proportion of glow plasma, the higher the concentration of produced $\mathrm{NO}_{x}$ was. After 10 min of discharge treatment, the maximum $\mathrm{NO}_{x}$ content in the chamber reached $6000 \mathrm{ppm}$ [82]. In comparison, Janda et al. obtained an $\mathrm{NO}_{x}$ concentration of $1000 \mathrm{ppm}$ without a gas chamber for discharge [83]. A mixture of nitrogen and oxygen ( $20 \%$ oxygen, $80 \%$ nitrogen) was used as feeding gas source, and spark discharge was carried out at a flow rate of $1.3-2.6 \mathrm{~L} / \mathrm{min}$. Under a low power of $0-6 \mathrm{~W}$, the output of $\mathrm{NO}_{x}$ was $100-600 \mathrm{ppm}$, and its energy consumption was also relatively low at $8.6 \mathrm{MJ} / \mathrm{molN}$ (see Fig. 8).

The structural parameters of the electrodes and the form of the power supply greatly affect spark discharge, so an optimized design of the discharge device can enhance the yield of $\mathrm{NO}_{x}$. For example, the pin-to-plane spark discharge adopted by Pei et al. can achieve an energy consumption of $5.2 \mathrm{MJ} / \mathrm{molN}$ at a power of 4-5 W [84] (see Fig. 9).

DBD, which is widely used in ammonia synthesis, is also used for the synthesis of $\mathrm{NO}_{x}$. Similar to the case of spark discharge, gas flow in DBD is usually treated in a limited volume space. The power in DBD is usually higher than that in spark discharge, producing a good treatment effect in a shorter time. If $\gamma-\mathrm{Al}_{2} \mathrm{O}_{3}$ is used as a discharge medium, and a high-oxygen-content $\mathrm{N}_{2} / \mathrm{O}_{2}$ (50\% oxygen) mixture is used as a raw material, $\mathrm{DBD}$ can output $\mathrm{NO}_{x}$ gas at nearly $6000 \mathrm{ppm}$, with a gas residence time of $0.4 \mathrm{~s}$ [85]. However, the energy loss is high, and the energy efficiency is lower than that of some of the above-mentioned spark discharges. Therefore, DBD also has the pain point of low treatment capacity and yield. DBD performance is influenced by various discharge parameters. Han et al. utilized DBD to treat air. Under a $45-145 \mathrm{~W}$ discharge power and 2 min treatment time, the $\mathrm{NO}_{x}$ concentration range was only 90-830 ppm, and the ozone concentration was 2-3 times of $\mathrm{NO}_{x}$ [86]. After discharge, $\mathrm{NO}$ is easily oxidized by $\mathrm{O}_{3}$ to form $\mathrm{NO}_{2}$. The concentration of $\mathrm{NO}_{2}$ increases, while the concentrations of $\mathrm{O}_{3}$ and $\mathrm{NO}$ both decrease, and the content of $\mathrm{O}_{3}$ relative to $\mathrm{NO}_{x}$ decreases significantly [87]. Tang et al. discharged a nitrogen-oxygen mixture (6\% oxygen) under a power of about $24 \mathrm{~W}$; the concentration of $\mathrm{NO}_{x}$ in $0.3 \mathrm{~L} / \mathrm{min}$ gas was below $400 \mathrm{ppm}$ [88]. This shows that DBD is not suitable for $\mathrm{NO}_{x}$ synthesis, but the advantages of an easy combination with a catalyst should not be ignored in further research.

Low-temperature arc discharge is a promising method for $\mathrm{NO}_{x}$ synthesis, as it can provide high energy density electrons in non-equilibrium state. For a given range of reduced electrical field, a large proportion of electron energy in the arc discharge is utilized in the process of vibrational excitation [76], up to more than $90 \%$. This means a greater proportion of energy goes into nitrogen cracking, which is conducive to improving the reaction efficiency and reducing energy loss. When using an $\mathrm{N}_{2} / \mathrm{O}_{2}$ mixed gas as gas source, and only $12-40 \mathrm{~W}$ discharge power as the input power, 2000-14,000 ppm $\mathrm{NO}_{x}$ gas can be synthesized by blade gliding arc discharge. The treatment capacity is $0.5-1 \mathrm{~L} / \mathrm{min}$ [89]. When the nitrogen supply accounts for $50 \%$ of the mixture, and the treatment capacity is $0.5 \mathrm{~L} / \mathrm{min}$, the $\mathrm{NO}_{x}$ concentration peaks, and the optimum energy consumption is $4.8 \mathrm{MJ} / \mathrm{molN}$ at $1 \mathrm{~L} / \mathrm{min}$. This means that 


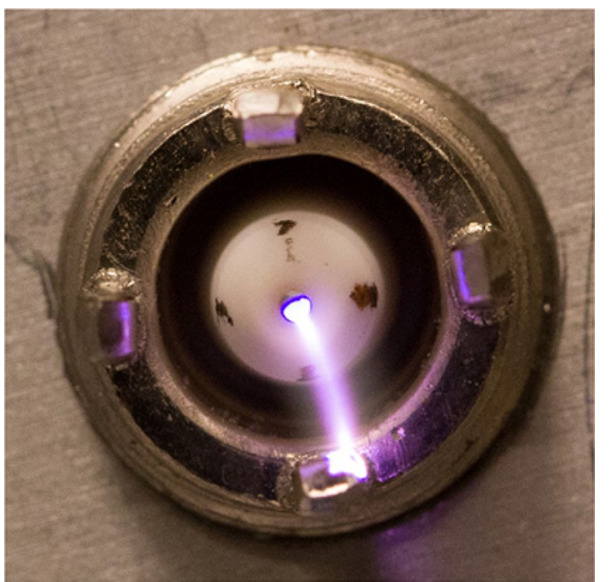

Fig. 8 Spark-like discharge device. Reprinted from [82] with permission

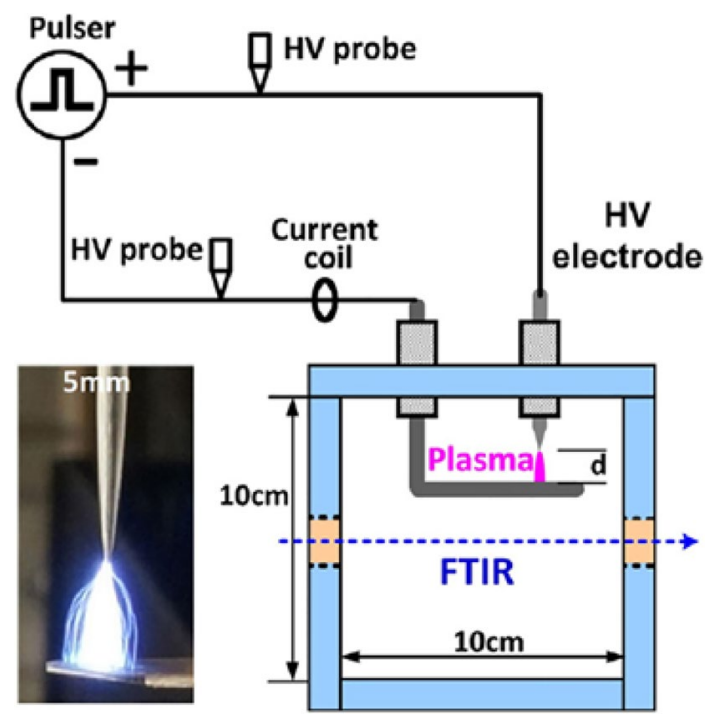

Fig. 9 The pin-to-plane spark discharge system. Reprinted from [84] with permission

gliding arc discharge has a better synthesis performance compared with other discharge techniques. In a similar study on gliding arc air discharge, a high concentration of $\mathrm{NO}_{x}$ can be synthesized with a high flow rate [90]. The air discharge was carried out at power of $240 \mathrm{~W}$. The air, discharged at a rate of $20 \mathrm{~L} / \mathrm{min}$, can contain up to $7600 \mathrm{ppm} \mathrm{NO}_{2}$. Propeller arc (PA) designed by Pei et al. also delivered a good synthesis performance, outputting $4462 \mathrm{ppm}$ of $\mathrm{NO}_{x}$ gas at a capacity of $3 \mathrm{~L} / \mathrm{min}$ [84]. It is worth mentioning that, in contrast with Patil's results, the best discharge effect of PA was obtained when the discharge atmosphere comprises air, or a mixture close to air, which reduces the cost of gas supply. When the ratio of $\mathrm{N}_{2}$ to $\mathrm{O}_{2}$ was 2 , the optimal energy consumption was $3.54 \mathrm{MJ} / \mathrm{molN}$. Although low-temperature arc discharge is not economically feasible to be applied in industrial synthetic ammonia, it is still one of the most efficient systems in the field of plasma nitrogen fixation under atmospheric conditions.

Jet plasma, which is similar to arc discharge, is also capable of attaining a high energy density and processing capacity. The plasma torch designed by Korolev et al. can work at a very large flow rate of $8.8-66 \mathrm{~L} / \mathrm{min}$ to discharge air and obtain $\mathrm{NO}_{x}$ that is no less than $1000 \mathrm{ppm}$ (1000-3500 ppm). The device only requires a $65-165 \mathrm{~W}$ power input, making it reasonably energy efficient. The lowest nitrogen fixation energy consumption is 3.4 MJ/molN [91]. The design of jet plasma devices varies, meaning that they do not generally match one another with respect to levels of synthesis. The $\mathrm{NO}_{x}$ concentration produced by a plasma jet is usually below $1000 \mathrm{ppm}[92$, 93]. Air jet plasma is usually studied for medical purposes including wound treatment. Instead of seeking a high $\mathrm{NO}_{x}$ concentration, air jet plasma focuses on obtaining a reasonable proportion of $\mathrm{NO}$ in produced $\mathrm{NO}_{x}$. The effective medical ingredient is $\mathrm{NO}$, rather than other nitrogen oxides. Portability and usability of the device have also been considered; therefore, in the field of NO synthesis, jet devices with low-power consumption and small size have provoked great interest (see Fig. 10).

Microwave plasma is another kind of plasma with a high energy density and high non-equilibrium state, but the degree of non-equilibrium state is related to the discharge gas pressure. At low pressure, the value of $\mathrm{T}_{\mathrm{v}} /$ $\mathrm{T}_{\mathrm{r}}$ (vibrational temperature to rotational temperature) is quite high. As the pressure increases, microwave plasma becomes similar to the thermal equilibrium state, and the rotational energy and vibrational energy of $\mathrm{N}_{2}$ tend to be the same [95]. This is relatively unfavorable for nitrogen activation. Lee et al. used electrodeless microwave plasma in $\mathrm{N}_{2} / \mathrm{O}_{2}$ discharge, achieving 9380 ppm $\mathrm{NO}_{x}$ with a low oxygen content (3\%) and a high treatment capacity (25 L/min) [96]. However, due to the ultra-high-power input $(2 \mathrm{~kW})$, the energy consumption level was not reduced by high output. Similar to most other studies, the energy consumption decreased with increasing treatment capacity, and the output concentration had a negative correlation with treatment capacity. High concentration and high energy efficiency could not be achieved at the same time. Obviously, the effect of $\mathrm{NO}_{x}$ synthesis by microwave plasma discharge is positively correlated with the SEI (specific energy input, i.e., the energy input per unit volume of gas). This characteristic is similar to that of other plasmas, like gliding arc plasmas [89, 97]. A high energy input means that the discharge gas is excited to a high degree, with more ionization, more electrons, more metastable state particles, and more excited molecules and 
other active particles. However, the non-equilibrium state will be weakened and the amount of energy converted into heat will increase. When the energy density increases, the benefit brought by the input energy has only a marginal effect on yield that does not grow linearly [84, 96, 98]. The energy density increase is usually related to a decreased energy efficiency. Rousseau et al. adopted air microwave plasma to produce $6000 \mathrm{ppm} \mathrm{NO}_{x}$. In the research of Kim et al., the concentration of $\mathrm{NO}_{x}$ produced by air microwave plasma was in the range of 3300-4600 ppm [99]. The lowest energy consumption was $3.76 \mathrm{MJ} / \mathrm{molN}$. The power of both systems was less than $100 \mathrm{~W}$, but the treatment capacities were relatively low $(0.25 \mathrm{~L} / \mathrm{min}$ and $6 \mathrm{~L} / \mathrm{min})$. Moreover, in Kim's research, when oxygen accounts for $30 \%$ of the feeding gas, the highest energy utilization rate of nitrogen fixation can be achieved. Compared with the $50 \%$ oxygen discharge conditions in the above-mentioned studies, it is helpful to reduce the raw material cost.

Corona discharge, streamer discharge, and other forms of discharge have also been studied [81, 100]. Although these discharge types are more similar to the natural nitrogen fixation by lightning, the product concentration and the energy efficiency are far less than those of gliding arc, jet, and microwave plasmas in the laboratory. Moreover, a large amount of ozone can be generated in these plasmas. Clearly, they are not suitable for artificial nitrogen fixation. Inductively coupled RF plasma discharge is usually carried out at low pressure; the conditions are relatively harsh, the processing capacity is small, and the effect is not significant $[70,73,75]$. Better results might be achieved by increasing reaction pressure [101] (see Table 4).

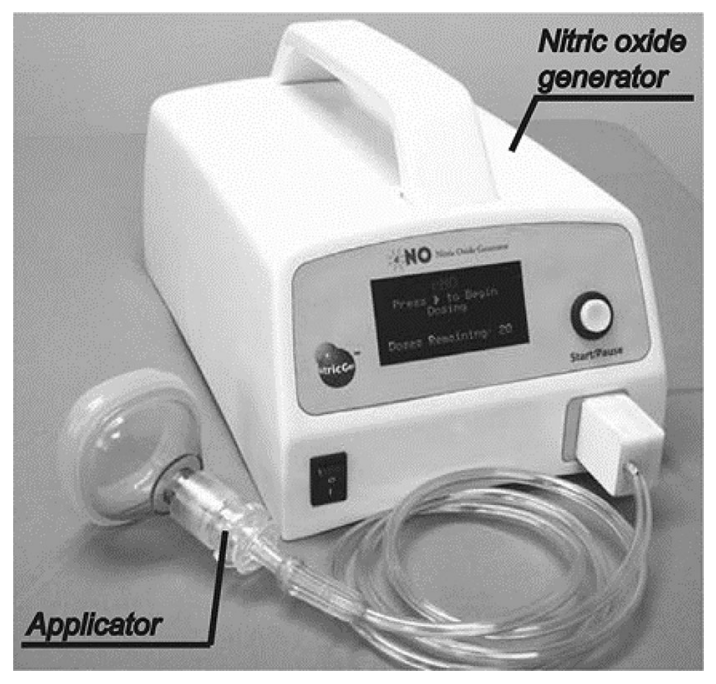

Fig. 10 Apparatus for NO therapy of Nitric Generation Technologies. Reprinted from [94] with permission

\section{Prospects of low-temperature plasma-based nitrogen fixation technologies}

In general, nitrogen fixation by a low-temperature plasma has various forms and is easy to implement. It can be realized without the need for high temperatures, high pressures, or complex procedures. Low-temperature plasma nitrogen fixation devices have the potential to realize the decentralization and localization of the nitrogen fixation industry in remote areas. This could substantially supplement the Haber-Bosch process, reducing the consumption of fossil resources and greenhouse gas emissions inherent to the current nitrogen fixation industry. With the rapid development of renewable anergy, the use of wind energy and solar energy can reduce the energy cost of discharge, as well as solving the problem of 'abandoning wind and light', which makes the development prospect more promising.

Although the future is bright, there is still a long way to go between low-temperature plasma nitrogen fixation and industrialization. Apart from the PAW treatment of plant seeds and other similar practical applications, most low-temperature plasma nitrogen fixation methods remain immature. The energy utilization rate of plasma nitrogen fixation is still very low. At normal temperatures and pressures, the energy consumption of low-temperature plasma nitrogen fixation is much higher than its theoretical energy consumption limit, and is not nearly as good as that of Haber-Bosch ammonia synthesis. Even if combined with renewable energy, a large amount of energy consumption cannot be ignored. Moreover, the application prospects of low-temperature plasma nitrogen fixation are restricted by production scale. In laboratory research, especially in plasma ammonia synthesis, the nitrogen treatment capacity is too small to meet production demand. For actual production, with a normal power supply, the normal operation of a device, while maintaining nitrogen fixation efficiency after the scale-up of instruments and energy, is still a core problem. For ammonia synthesis, the preparation of catalysts is needed, which will further increase cost. The concentration of $\mathrm{NO}_{x}$ will be a limiting factor in oxidation-type nitrogen fixation. The $\mathrm{NO}_{x}$ concentration is only about $1 \%$ in gaseous products, which might force some constraints on products utilization like nitric acid production. For PAW, the tension between component concentration and water volume is also problematic. Due to the diversity of activated water properties and the medical application of NO, the utilization of oxidation-type nitrogen fixation by plasma is approaching the level of practical application.

With further study of relevant theories, such as the formation/loss mechanisms of $\mathrm{NH}_{3}$ and $\mathrm{NO}_{x}$ in plasma, it is 
Table 4 Nitrogen fixation output of plasma gas -phase oxidation

\begin{tabular}{|c|c|c|c|c|c|}
\hline Plasma & Supply gas & Air flow rate (L/min) & $\begin{array}{l}\mathrm{NO}_{x} \text { concentra- } \\
\text { tion }(\mathrm{ppm})\end{array}$ & $\begin{array}{l}\text { Optimal energy consump- } \\
\text { tion }\left(\mathrm{MJ} / \mathrm{mol} \mathrm{NO}_{x}\right)\end{array}$ & Source \\
\hline Spark & Air & Batch (10 min) & $2000-6300$ & 40 & Pavlovich et al. [82] \\
\hline Streamer & Air & - & - & 30.1 & Cooray et al. [100] \\
\hline Spark & Air & Batch (15 min) & - & 20.3 & Cooray et al. [81] \\
\hline DBD & $\mathrm{N}_{2} / \mathrm{O}_{2}$ mixture & Batch (6-7 min) & 6000 & 20 & Patil et al. [85] \\
\hline Microwave & $\mathrm{N}_{2} / \mathrm{O}_{2}$ mixture & $25-45$ & $1612-9380$ & 9.6 & Lee et al. [96] \\
\hline Spark & $\mathrm{N}_{2} / \mathrm{O}_{2}$ mixture & $1.3-2.6$ & $100-600$ & 8.6 & Janda et al. [83] \\
\hline Jet & Air & $0.25-8$ & $100-1000$ & 8.6 & Kolb et al. [92] \\
\hline Glow & Air & 2 & - & 7 & Pei et al. [84] \\
\hline Spark & - & Batch- & - & 5.2 & Pei et al. [84] \\
\hline Gliding arc & $\mathrm{N}_{2} / \mathrm{O}_{2}$ mixture & $0.5-1$ & $2000-14,000$ & 4.8 & Patil et al. [89] \\
\hline Microwave & Air & 6 & $3347-4512$ & 3.76 & Kim et al. [99] \\
\hline Propeller arc & Air, $\mathrm{N}_{2} / \mathrm{O}_{2}$ & 3 & $0-4462$ & 3.54 & Pei et al. [84] \\
\hline Jet & Air & $8.8-66$ & $1000-3500$ & 3.4 & Korolev et al. [91] \\
\hline Plasmatron & $\mathrm{N}_{2} / \mathrm{O}_{2}$ mixture & 10 & 15,000 & 3.6 & Vervloessem et al. [102] \\
\hline Rotating gliding arc & $\mathrm{N}_{2} / \mathrm{O}_{2}$ mixture & 2 & 55,000 & 2.5 & Jardali et al. [103] \\
\hline
\end{tabular}

believed that better plasma nitrogen fixation schemes will be proposed. Reducing the decomposition effect of plasma on $\mathrm{NH}_{3}$, improving the absorption and separation of $\mathrm{NH}_{3}$ in the reactor are key in improving the nitrogen fixation yield. Optimizing and controlling the properties of plasma (such as discharge form and energy density), and regulating and controlling the conversion of input energy (more for vibrational excitation, less for heat) could improve energy efficiency. Conducting further mechanism research and effect optimization of gas quenching are necessary, as well. Optimization of these parameters will provide a breakthrough for the industrialization of plasma nitrogen fixation.

Funding The funding has been recevied from National Natural Science Foundation of China with Grant No. 51806193; National Natural Science Foundation of China with Grant No. 51976191.

\section{Declarations}

Conflict of interest The authors report no declarations of interest.

\section{References}

1. Cherkasov, N., Ibhadon, A.O., and Fitzpatrick, P. 2015. A review of the existing and alternative methods for greener nitrogen fixation. Chemical Engineering and Processing: Process Intensification 90: 24-33.

2. Tanabe, Y., and Nishibayashi, Y. 2013. Developing more sustainable processes for ammonia synthesis. Coordination Chemistry Reviews 257: 2551-2564.
3. Fowler, D., Coyle, M., Skiba, U., et al. 2013. The global nitrogen cycle in the twenty-first century. Philosophical Transactions of the Royal Society B: Biological Sciences 368: 20130164.

4. Aihara, K., Akiyama, M., Deguchi, T., et al. 2016. Remarkable catalysis of a wool-like copper electrode for $\mathrm{NH}_{3}$ synthesis from $\mathrm{N}_{2}$ and $\mathrm{H}_{2}$ in non-thermal atmospheric plasma. Chemical Communications (Cambridge, England) 52: 13560-13563.

5. Rouwenhorst, K.H.R., Kim, H.-H., and Lefferts, L. 2019. Vibrationally excited activation of $\mathrm{N}_{2}$ in plasma-enhanced catalytic ammonia synthesis: A kinetic analysis. ACS Sustainable Chemistry \& Engineering 7: 17515-17522.

6. Mehta, P., Barboun, P., Herrera, F.A., et al. 2018. Overcoming ammonia synthesis scaling relations with plasma-enabled catalysis. Nature Catalysis 1: 269-275.

7. Akay, G., and Zhang, K. 2017. Process intensification in ammonia synthesis using novel coassembled supported microporous catalysts promoted by nonthermal plasma. Industrial \& Engineering Chemistry Research 56: 457-468.

8. Bai, M.D., Bai, X.Y., and Zhang, Z.T. 2000. Synthesis of ammonia in a strong electric field discharge at ambient pressure. Plasma Chemistry and Plasma Processing 20: 511-520.

9. Herrera, F.A., Brown, G.H., Barboun, P., et al. 2019. The impact of transition metal catalysts on macroscopic dielectric barrier discharge (DBD) characteristics in an ammonia synthesis plasma catalysis reactor. Journal of Physics D: Applied Physics 52: 224002.

10. Gómez-Ramírez, A., Cotrino, J., Lambert, R.M., et al. 2015. Efficient synthesis of ammonia from $\mathrm{N}_{2}$ and $\mathrm{H}_{2}$ alone in a ferroelectric packed-bed DBD reactor. Plasma Sources Science and Technology 24: 065011.

11. Barboun, P., Mehta, P., Herrera, F.A., et al. 2019. Distinguishing plasma contributions to catalyst performance in plasma-assisted ammonia synthesis. ACS Sustainable Chemistry \& Engineering 7: 8621-8630.

12. Bai, M.D., Zhang, Z.T., Bai, X.Y., et al. 2003. Plasma synthesis of ammonia with a microgap dielectric barrier discharge at ambient pressure. IEEE Transactions on Plasma Science 31: $1285-1291$. 
13. Hong, J., Prawer, S., and Murphy, A.B. 2014. Production of ammonia by heterogeneous catalysis in a packed-bed dielectricbarrier discharge: Influence of argon addition and voltage. IEEE Transactions on Plasma Science 42: 2338-2339.

14. Kerpal, C., Harding, D.J., Lyon, J.T., et al. 2013. $\mathrm{N}_{2}$ activation by neutral ruthenium clusters. The Journal of Physical Chemistry $C$ 117: $12153-12158$

15. Kitano, M., Inoue, Y., Yamazaki, Y., et al. 2012. Ammonia synthesis using a stable electride as an electron donor and reversible hydrogen store. Nature Chemistry 4: 934-940.

16. Mizushima, T., Matsumoto, K., Sugoh, J.-I., et al. 2004. Tubular membrane-like catalyst for reactor with dielectric-barrierdischarge plasma and its performance in ammonia synthesis. Applied Catalysis A: General 265: 53-59.

17. Kim, H.-H., Teramoto, Y., Ogata, A., et al. 2017. Atmosphericpressure non-thermal plasma synthesis of ammonia over ruthenium catalysts. Plasma Processes and Polymers 14: 1600157.

18. Li, S., van Raak, T., and Gallucci, F. 2020. Investigating the operation parameters for ammonia synthesis in dielectric barrier discharge reactors. Journal of Physics D: Applied Physics 53: 014008 .

19. Peng, P., Li, Y., Cheng, Y., et al. 2016. Atmospheric pressure ammonia synthesis using non-thermal plasma assisted catalysis. Plasma Chemistry and Plasma Processing 36: 1201-1210.

20. Iwamoto, M., Akiyama, M., Aihara, K., et al. 2017. Ammonia synthesis on wool-like $\mathrm{Au}, \mathrm{Pt}, \mathrm{Pd}, \mathrm{Ag}$, or $\mathrm{Cu}$ electrode catalysts in nonthermal atmospheric-pressure plasma of $\mathrm{N}_{2}$ and $\mathrm{H}_{2}$. ACS Catalysis 7: 6924-6929.

21. Hong, J., Aramesh, M., Shimoni, O., et al. 2016. Plasma catalytic synthesis of ammonia using functionalized-carbon coatings in an atmospheric-pressure non-equilibrium discharge. Plasma Chemistry and Plasma Processing 36: 917-940.

22. De Castro, A., and Tabarés, F.L. 2018. Role of nitrogen inventory and ion enhanced $\mathrm{N}-\mathrm{H}$ recombination in the ammonia formation on tungsten walls. A DC glow discharge study. Vacuum 151: 66-72.

23. Nakajima, J., and Sekiguchi, H. 2008. Synthesis of ammonia using microwave discharge at atmospheric pressure. Thin Solid Films 516: 4446-4451.

24. Xie, Q., Zhuge, S., Song, X., et al. 2020. Non-thermal atmospheric plasma synthesis of ammonia in a DBD reactor packed with various catalysts. Journal of Physics D: Applied Physics 53: 064002.

25. Peng, P., Chen, P., Addy, M., et al. 2018. Atmospheric plasmaassisted ammonia synthesis enhanced via synergistic catalytic absorption. ACS Sustainable Chemistry \& Engineering 7: 100-104.

26. Gómez-Ramírez, A., Montoro-Damas, A.M., Cotrino, J., et al. 2017. About the enhancement of chemical yield during the atmospheric plasma synthesis of ammonia in a ferroelectric packed bed reactor. Plasma Processes and Polymers 14: 1600081.

27. Carreon, M.L., Jaramillo-Cabanzo, D.F., Chaudhuri, I., et al. 2018. Synergistic interactions of $\mathrm{H}_{2}$ and $\mathrm{N}_{2}$ with molten gallium in the presence of plasma. Journal of Vacuum Science \& Technology A: Vacuum, Surfaces, and Films 36: 021303.

28. Shah, J., Wang, W., Bogaerts, A., et al. 2018. Ammonia synthesis by radio frequency plasma catalysis: Revealing the underlying mechanisms. ACS Applied Energy Materials 1: 4824-4839.

29. Shah, J., Wu, T., Lucero, J., et al. 2018. Nonthermal plasma synthesis of ammonia over Ni-MOF-74. ACS Sustainable Chemistry \& Engineering 7: 377-383.

30. Ma, Z.-Y., Feng, P., Gao, Q.-X., et al. 2015. $\mathrm{CH}_{4}$ emissions and reduction potential in wastewater treatment in China. Advances in Climate Change Research 6: 216-224.

31. Gorbanev, Y., Vervloessem, E., Nikiforov, A., et al. 2020. Nitrogen fixation with water vapor by nonequilibrium plasma: toward sustainable ammonia production. ACS Sustainable Chemistry \& Engineering 8: 2996-3004.

32. Sakakura, T., Uemura, S., Hino, M., et al. 2018. Excitation of $\mathrm{H}_{2} \mathrm{O}$ at the plasma/water interface by UV irradiation for the elevation of ammonia production. Green Chemistry 20: 627-633.

33. Peng, P., Schiappacasse, C., Zhou, N., et al. 2019. Sustainable non-thermal plasma-assisted nitrogen fixation-synergistic catalysis. Chemsuschem 12: 3702-3712.

34. Kubota, Y., Koga, K., Ohno, M., et al. 2010. Synthesis of ammonia through direct chemical reactions between an atmospheric nitrogen plasma jet and a liquid. Plasma and Fusion Research 5: 042 .

35. Hawtof, R., Ghosh, S., Guarr, E., et al. 2019. Catalyst-free, highly selective synthesis of ammonia from nitrogen and water by a plasma electrolytic system. Science Advances 5: eaat5778.

36. Seinfeld, J.H., and Pandis, S.N. 1998. Atmospheric chemistry and physics, from air pollution to climate change. Hoboken, NJ, USA. Wiley.

37. Burlica, R., Kirkpatrick, M.J., and Locke, B.R. 2006. Formation of reactive species in gliding arc discharges with liquid water. Journal of Electrostatics 64: 35-43.

38. Fridman, A. 2008. Plasma Chemistry I. Cambridge, UK: Cambridge University Press.

39. Brisset, J.-L., and Hnatiuc, E. 2012. Peroxynitrite: A re-examination of the chemical properties of non-thermal discharges burning in air over aqueous solutions. Plasma Chemistry and Plasma Processing 32: 655-674.

40. Thirumdas, R., Kothakota, A., Annapure, U., et al. 2018. Plasma activated water (PAW): Chemistry, physico-chemical properties, applications in food and agriculture. Trends in Food Science \& Technology 77: 21-31.

41. Li, Z., Ohno, T., Sato, H., et al. 2008. A method of waterbloom prevention using underwater pulsed streamer discharge. Journal of Environmental Science and Health. Part A, Toxic/ Hazardous Substances \& Environmental Engineering 43: 1209-1214.

42. Naitali, M., Kamgang-Youbi, G., Herry, J.M., et al. 2010. Combined effects of long-living chemical species during microbial inactivation using atmospheric plasma-treated water. Applied and Environment Microbiology 76: 7662-7664.

43. Van Gils, C.A.J., Hofmann, S., Boekema, B.K.H.L., et al. 2013. Mechanisms of bacterial inactivation in the liquid phase induced by a remote RF cold atmospheric pressure plasma jet. Journal of Physics D: Applied Physics 46: 175203.

44. Tian, Y., Ma, R., Zhang, Q., et al. 2015. Assessment of the physicochemical properties and biological effects of water activated by non-thermal plasma above and beneath the water surface. Plasma Processes and Polymers 12: 439-449.

45. Brisset, J.-L., and Pawlat, J. 2016. Chemical effects of air plasma species on aqueous solutes in direct and delayed exposure modes: discharge, post-discharge and plasma activated water. Plasma Chemistry and Plasma Processing 36: 355-381.

46. Pryor, W.A., and Squadrito, G. 1995. The chemistry of peroxynitrite and peroxynitrous acid: Products from the reaction of nitric oxide with superoxide. American Journal of Physiology 268: L699-L721.

47. Katsumura, Y. 1998. $\mathrm{NO}_{2}$ and $\mathrm{NO}_{3}$ radicals in radiolysis of nitric acid solutions. In The Chemistry of Free Radicals $N$-Centered Radicals, ed. Alfassi ZB, 393-412. Chichester, UK. Wiley.

48. Graves, D.B., Bakken, L.B., Jensen, M.B., et al. 2018. Plasma activated organic fertilizer. Plasma Chemistry and Plasma Processing 39: 1-19.

49. Laurita, R., Barbieri, D., Gherardi, M., et al. 2015. Chemical analysis of reactive species and antimicrobial activity of water treated by nanosecond pulsed DBD air plasma. Clinical Plasma Medicine 3: 53-61. 
50. Tarabová, B., Lukeš, P., Janda, M., et al. 2018. Specificity of detection methods of nitrites and ozone in aqueous solutions activated by air plasma. Plasma Processes and Polymers 15: 180030.

51. Lukes, P., Dolezalova, E., Sisrova, I., et al. 2014. Aqueous-phase chemistry and bactericidal effects from an air discharge plasma in contact with water: evidence for the formation of peroxynitrite through a pseudo-second-order post-discharge reaction of $\mathrm{H}_{2} \mathrm{O}_{2}$ and $\mathrm{HNO}_{2}$. Plasma Sources Science and Technology 23: 015019.

52. Ingels, R., and Graves, D. 2016. Improving the efficiency of organic fertilizer and nitrogen use via air plasma and distributed renewable energy. Plasma Medicine 5: 257-270.

53. Bruggeman, P., and Leys, C. 2009. Non-thermal plasmas in and in contact with liquids. Journal of Physics D: Applied Physics 42: 053001

54. Benstaali, B., Moussa, D., Addou, A., et al. 1998. Plasma treatment of aqueous solutes: Some chemical properties of a gliding arc in humid air. The European Physical Journal Applied Physics 4: $171-179$

55. Lindsay, A., Byrns, B., King, W., et al. 2014. Fertilization of radishes, tomatoes, and marigolds using a large-volume atmospheric glow discharge. Plasma Chemistry and Plasma Processing 34: 1271-1290.

56. Peng, P., Chen, P., Addy, M., et al. 2018. In situ plasma-assisted atmospheric nitrogen fixation using water and spray-type jet plasma. Chemical Communications (Cambridge, England) 54: 2886-2889.

57. Lukes, P., Clupek, M., Babicky, V., et al. 2008. Ultraviolet radiation from the pulsed corona discharge in water. Plasma Sources Science and Technology 17: 024012.

58. Peng, P., Schiappacasse, C., Zhou, N., et al. 2019. Plasma in situ gas-liquid nitrogen fixation using concentrated high-intensity electric field. Journal of Physics D: Applied Physics 52: 494001.

59. Wandell, R.J., and Locke, B.R. 2014. Low-power pulsed plasma discharge in a water film reactor. IEEE Transactions on Plasma Science 42: 2634-2635.

60. Wandell, R.J., Wang, H., Bulusu, R.K.M., et al. 2019. Formation of nitrogen oxides by nanosecond pulsed plasma discharges in gas-liquid reactors. Plasma Chemistry and Plasma Processing 39: 643-666.

61. Burlica, R., Grim, R.G., Shih, K.Y., et al. 2010. Bacteria inactivation using low power pulsed gliding arc discharges with water spray. Plasma Processes and Polymers 7: 640-649.

62. Burlica, R., Shih, K.Y., and Locke, B. 2010. Formation of $\mathrm{H}_{2}$ and $\mathrm{H}_{2} \mathrm{O}_{2}$ in a water-spray gliding arc nonthermal plasma reactor. Industrial \& Engineering Chemistry Research 49: 6342-6349.

63. Bian, W.J., and Yin, X.L., 2007. Nitrogen fixation into $\mathrm{HNO}_{3}$ and $\mathrm{HNO}_{2}$ by pulsed high voltage discharge. J Plasma Science and Technology 9: 288-291.

64. Babayan, S.E., Ding, G., and Hicks, R.F. 2001. Determination of the nitrogen atom density in the afterglow of a nitrogen and helium nonequilibrium, atmospheric pressure plasma. Plasma Chemistry and Plasma Processing 21: 505-521.

65. Wakeford, C.A., Blackburn, R., and Lickiss, P.D. 1999. Effect of ionic strength on the acoustic generation of nitrite, nitrate and hydrogen peroxide. Ultrasonics Sonochemistry 6: 141-148.

66. Yang, J., Li, T., Chongshan, Z., et al. 2016. Nitrogen fixation in water using air phase gliding arc plasma. Journal of The Electrochemical Society 163: E288-E292.

67. Park, D.P., Davis, K., Gilani, S., et al. 2013. Reactive nitrogen species produced in water by non-equilibrium plasma increase plant growth rate and nutritional yield. Current Applied Physics 13: S19-S29.

68. Thagard, S.M., Takashima, K., and Mizuno, A. 2009. Chemistry of the positive and negative electrical discharges formed in liquid water and above a gas-liquid surface. Plasma Chemistry and Plasma Processing 29: 455-473.
69. Yoon, S.Y., Jeon, H., Yi, C., et al. 2018. Mutual interaction between plasma characteristics and liquid properties in ACdriven pin-to-liquid discharge. Science Reports 8: 12037.

70. Van Ham, B.T.J., Hofmann, S., Brandenburg, R., et al. 2014. In situ absolute air, $\mathrm{O}_{3}$ and $\mathrm{NO}$ densities in the effluent of a cold $\mathrm{RF}$ argon atmospheric pressure plasma jet obtained by molecular beam mass spectrometry. Journal of Physics D: Applied Physics 47: 224013.

71. Malik, M. 2016. Nitric oxide production by high voltage electrical discharges for medical uses: A review. Plasma Chemistry and Plasma Processing 36: 737-766.

72. Li, S., Medrano Jimenez, J., Hessel, V., et al. 2018. recent progress of plasma-assisted nitrogen fixation research: A review. Processes 6: 248.

73. Gatilova, L.V., Allegraud, K., Guillon, J., et al. 2007. NO formation mechanisms studied by infrared laser absorption in a single low-pressure plasma pulse. Plasma Sources Science and Technology 16: S107-S114.

74. Pintassilgo, C.D., and Guerra, V. 2019. Kinetic mechanisms in air plasmas. Plasma Physics and Controlled Fusion 61: 014026.

75. Hübner, M., Gortschakow, S., Guaitella, O., et al. 2016. Kinetic studies of NO formation in pulsed air-like low-pressure dc plasmas. Plasma Sources Science and Technology 25: 035005.

76. Wang, W., Patil, B., Heijkers, S., et al. 2017. Nitrogen fixation by gliding arc plasma: Better insight by chemical kinetics modelling. Chemsuschem 10: 2145-2157.

77. Popov, N.A. (2011) Fast gas heating in a nitrogen-oxygen discharge plasma: I. Kinetic mechanism. Journal of Physics D: Applied Physics 44: 285201.

78. Xie, W. 2008. Spectroscopic diagnostics of active species and their environmental chemical process of $\mathrm{O}_{2}, \mathrm{~N}_{2}, \mathrm{CO}_{2}$ in cold plasma. Shanghai, China: Shanghai Jiao Tong University.

79. Rusanov, V.D., Fridman, A.A., and Sholin, G.V. 1981. The physics of a chemically active plasma with non-equilibrium vibrational excitation of molecules. Soviet Physics Uspekhi 24: 447-474.

80. Anastasopoulou, A., Butala, S., Lang, J., et al. 2016. Life cycle assessment of the nitrogen fixation process assisted by plasma technology and incorporating renewable energy. Industrial \& Engineering Chemistry Research 55: 8141-8153.

81. Rehbein, N., and Cooray, V. 2001. $\mathrm{NO}_{\mathrm{x}}$ production in spark and corona discharges. Journal of Electrostatics 51-52: 333-339.

82. Pavlovich, M.J., Ono, T., Galleher, C., et al. 2014. Air sparklike plasma source for antimicrobial $\mathrm{NO}_{\mathrm{x}}$ generation. Journal of Physics D: Applied Physics 47: 505202.

83. Janda, M., Martišovitš, V., Hensel, K., et al. 2016. Generation of antimicrobial $\mathrm{NO}_{\mathrm{x}}$ by atmospheric air transient spark discharge. Plasma Chemistry and Plasma Processing 36: 767-781.

84. Pei, X., Gidon, D., Yang, Y.-J., et al. 2019. Reducing energy cost of $\mathrm{NO}_{\mathrm{x}}$ production in air plasmas. Chemical Engineering Journal 362: 217-228.

85. Patil, B.S., Cherkasov, N., Lang, J., et al. 2016. Low temperature plasma-catalytic $\mathrm{NO}_{\mathrm{x}}$ synthesis in a packed DBD reactor: Effect of support materials and supported active metal oxides. Applied Catalysis B: Environmental 194: 123-133.

86. Han, Y., Wen, S., Tang, H., et al. 2018. Influences of frequency on nitrogen fixation of dielectric barrier discharge in air. Plasma Science and Technology 20: 014001.

87. Park, S., Choe, W., and Jo, C. 2018. Interplay among ozone and nitrogen oxides in air plasmas: Rapid change in plasma chemistry. Chemical Engineering Journal 352: 1014-1021.

88. Tang, X., Wang, J., Yi, H., et al. 2018. Nitrogen fixation and NO conversion using dielectric barrier discharge reactor: identification and evolution of products. Plasma Chemistry and Plasma Processing 38: 485-501. 
89. Patil, B.S., Peeters, F.J.J., van Rooij, G.J., et al. 2018. Plasma assisted nitrogen oxide production from air: Using pulsed powered gliding arc reactor for a containerized plant. AIChE Journal 64: 526-537.

90. Bo, Z., Yan, J., Li, X., et al. 2009. Nitrogen dioxide formation in the gliding arc discharge-assisted decomposition of volatile organic compounds. Journal of Hazardous Materials 166: 1210-1216.

91. Korolev, Y.D., Frants, O.B., Landl, N.V., et al. 2012. Low-current plasmatron as a source of nitrogen oxide molecules. IEEE Transactions on Plasma Science 40: 2837-2842.

92. Hao, X., Mattson, A.M., Edelblute, C.M., et al. 2014. Nitric oxide generation with an air operated non-thermal plasma jet and associated microbial inactivation mechanisms. Plasma Processes and Polymers 11: 1044-1056.

93. Hu, Hui, Bao, B., Wang, H.L., et al. 2008. The effect of flow distribution on the concentration of NO produced by pulsed arc discharge. Plasma Science and Technology 9: 766.

94. Pekshev, A.V., Shekhter, A.B., Vagapov, A.B., et al. 2018. Study of plasma-chemical NO-containing gas flow for treatment of wounds and inflammatory processes. Nitric Oxide 73: 74-80.

95. Gatti, N., Ponduri, S., Peeters, F.J.J., et al. 2018. Preferential vibrational excitation in microwave nitrogen plasma assessed by Raman scattering. Plasma Sources Science and Technology 27: 055006

96. Lee, J., Sun, H., Im, S.-K., et al. 2017. Formation of nitrogen oxides from atmospheric electrodeless microwave plasmas in nitrogen-oxygen mixtures. Journal of Applied Physics 122: 083303 .

97. Pintassilgo, C., Guaitella, O., and Rousseau, A. 2009. Heavy species kinetics in low-pressure de pulsed discharges in air. Plasma Sources Science and Technology 18: 025005.

98. Rousseau, A., Dantier, A., Gatilova, L., et al. 2005. On $\mathrm{NO}_{\mathrm{x}}$ production and volatile organic compound removal in a pulsed microwave discharge in air. Plasma Sources Science and Technology 14: 70-75.

99. Kim, T., Song, S., Kim, J., et al. 2010. Formation of $\mathrm{NO}_{\mathrm{x}}$ from air and $\mathrm{N}_{2} / \mathrm{O}_{2}$ mixtures using a nonthermal microwave plasma system. Japanese Journal of Applied Physics 49: 126201.

100. Cooray, V., and Rahman, M. 2005. Efficiencies for production of $\mathrm{NO}_{\mathrm{x}}$ and $\mathrm{O}_{3}$ by streamer discharges in air at atmospheric pressure. Journal of Electrostatics 63: 977-983.

101. Matveev, I.B., and Serbin, S.I. 2019. Synthesis of nitrogen oxides in ICP/RF plasma. IEEE Transactions on Plasma Science 47: 47-51.

102. Vervloessem, E., Aghaei, M., Jardali, F., et al. 2020. Plasmabased $\mathrm{N}_{2}$ fixation into $\mathrm{NO}_{\mathrm{x}}$ : Insights from modeling toward optimum yields and energy costs in a gliding arc plasmatron. ACS Sustainable Chemistry \& Engineering 8: 9711-9720.

103. Jardali, F., van Alphen, S., Creel, J., et al. 2021. $\mathrm{NO}_{\mathrm{x}}$ production in a rotating gliding arc plasma: potential avenue for sustainable nitrogen fixation. Green Chemistry 23: 1748-1757.

Publisher's Note Springer Nature remains neutral with regard to jurisdictional claims in published maps and institutional affiliations. 